OECD Environment Working Papers No. 60

\title{
The Role of National \\ Ecosystem Assessments in Influencing Policy Making
}

\section{Lucy Wilson, \\ Cristina Secades, \\ Ulf Narloff,}

Nadine Bowles-Newark,

Abisha Mapendembe,

Hollie Booth,

Claire Brown,

Megan Tierney 
ENVIRONMENT DIRECTORATE

\section{OECD ENVIRONMENT WORKING PAPER No. 60 - THE ROLE OF NATIONAL ECOSYSTEM} ASSESSMENTS IN INFLUENCING POLICY MAKING

By Lucy Wilson, Cristina Secades, Dr. Ulf Narloff, Nadine Bowles-Newark, Abisha Mapendembe, Hollie Booth, Dr. Claire Brown, and Dr. Megan Tierney, of the World Conservation Monitoring Centre (WCMC)

OECD Working Papers should not be reported as representing the official views of the OECD or of its member countries. The opinions expressed and arguments employed are those of the author(s).

Authorised for publication by Simon Upton, Director, Environment Directorate.

JEL Classification: $Q 01, Q 28, Q 57$

Keywords: sustainable development, renewable resources and conservation - government policy, ecological economics - ecosystem services - biodiversity conservation

OECD Environment Working Papers are available at www.oecd.org/env/workingpapers.htm

JT03363281

Complete document available on OLIS in its original format

This document and any map included herein are without prejudice to the status of or sovereignty over any territory, to the delimitation of international frontiers and boundaries and to the name of any territory, city or area. 


\section{OECD ENVIRONMENT WORKING PAPERS}

OECD Working Papers should not be reported as representing the official views of the OECD or of its member countries. The opinions expressed and arguments employed are those of the authors.

Working Papers describe preliminary results or research in progress by the author(s) and are published to stimulate discussion on a broad range of issues on which the OECD works.

This series is designed to make available to a wider readership selected studies on environmental issues prepared for use within the OECD. Authorship is usually collective, but principal author(s) are named. The papers are generally available only in their original language -English or French- with a summary in the other.

Comments on Working Papers are welcomed, and may be sent to Environment Directorate, OECD, 2 rue André-Pascal, 75775 Paris Cedex 16, France or by contacting: env.contact@oecd.org.

\section{OECD Environment Working Papers are published on} www.oecd.org/env/workingpapers.htm

This document and any map included herein are without prejudice to the status of or sovereignty over any territory, to the delimitation of international frontiers and boundaries and to the name of any territory, city or area.

The statistical data for Israel are supplied by and under the responsibility of the relevant Israeli authorities. The use of such data by the OECD is without prejudice to the status of the Golan Heights, East Jerusalem and Israeli settlements in the West Bank under the terms of international law.

\section{(C) OECD (2014)}

You can copy, download or print OECD content for your own use, and you can include excerpts from OECD publications, databases and multimedia products in your own documents, presentations, blogs, websites and teaching materials, provided that suitable acknowledgment of OECD as source and copyright owner is given.

All requests for commercial use and translation rights should be submitted to rights@oecd.org. 
ENV/WKP(2014)9

\begin{abstract}
An ecosystem assessment is a social process through which the findings of science concerning the causes of ecosystem change, their consequences for human well-bring, and the management and policy options are evaluated. Ecosystem assessments can play an important role in synthesising and communicating complex information and can both inform and influence decision-making processes. This paper draws insights from experience with National Ecosystem Assessments (NEAs) recently undertaken in the UK, Japan, Spain, and Portugal, as well as other ecosystem assessments undertaken at regional and international geographical scales, and highlights lessons learned so that the impact of NEAs on policy can be enhanced. The paper concludes by identifying key issues needed to develop practical guidance for successful ecosystem assessments.
\end{abstract}

JEL classification: Q01, Q28, Q57

Keywords: sustainable development, renewable resources and conservation - government policy, ecological economics - ecosystem services - biodiversity conservation

\title{
RÉSUMÉ
}

Une évaluation des écosystèmes est un processus social visant à estimer les résultats de la recherche scientifique sur les causes des changements subis par les écosystèmes, leurs conséquences pour le bien-être humain, ainsi que les lignes d'action ou options de gestion possibles. En synthétisant et en véhiculant des informations complexes, les évaluations des écosystèmes peuvent à la fois éclairer et influencer les processus de décision. Ce document tire parti de l'expérience acquise dans le cadre des évaluations nationales des écosystèmes récemment réalisées au Royaume Uni, au Japon, en Espagne et au Portugal, ainsi que d'autres évaluations des écosystèmes entreprises à l'échelle régionale et internationale, et présente les enseignements qui s'en dégagent de façon à renforcer l'impact des évaluations nationales des écosystèmes sur l'action des pouvoirs publics. En conclusion, le document expose les principaux problèmes à résoudre pour élaborer un guide pratique pour la bonne évaluation des écosystèmes.

Classification JEL : Q01, Q28, Q57

Mots clés : développement durable, ressources renouvelables et leur conservation - politiques publiques, économie de l'écologie - services écosystémiques - préservation de la biodiversité 


\section{FOREWORD}

This paper examines the role of National Ecosystem Assessments (NEAs) in influencing policy making, and was commissioned by the Organisation for Economic Co-operation and Development (OECD). The main objective of the paper is to draw insights from experience in different countries of the added value to policy making of undertaking national level ecosystem assessments. The paper was prepared by Wilson et al. of the World Conservation Monitoring Centre (WCMC).

A first draft of this report served as a background paper for the joint General Commission for Sustainable Development (CGDD)-OECD seminar, The Assessment of Ecosystem Services and Its Use for Public Policies (1 February 2013, in Paris, France). Further information on the seminar, including presentations, is available at http://www.oecd.org/env/resources/biodiversityseminarfebruary2013.htm. 


\section{TABLE OF CONTENTS}

ABSTRACT
RÉSUMÉ...
FOREWORD
ACRONYMS
EXECUTIVE SUMMARY
$2.1 \quad$ WNTRODUCTION

3. CHALLENGES AND CONSIDERATIONS IN NATIONAL ECOSYSTEM ASSESSMENT

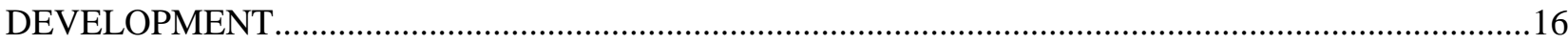

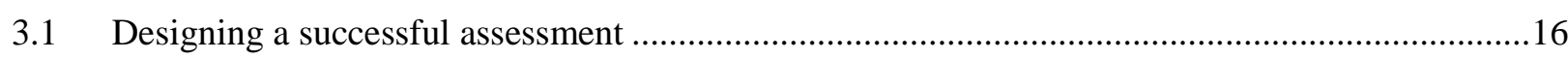

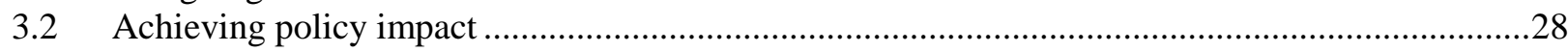

4. POLICY IMPACTS OF NATIONAL ECOSYSTEM ASSESSMENTS …...........................................

4.1 Impact of National Ecosystem Assessments at the national level.................................................31

4.2 Impact of National Ecosystem Assessments at the regional level ...............................................34

4.3 Impact of National Ecosystem Assessments at the international level ........................................35

5. LESSONS LEARNED FROM NATIONAL ECOSYSTEM ASSESSMENTS...................................37

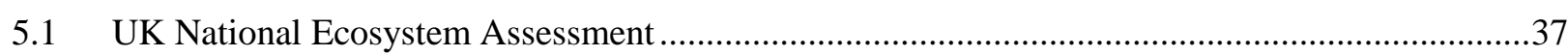

5.2 Lessons from the Portugal Millennium Ecosystem Assessment .....................................................39

5.3 Lessons from the Spanish National Ecosystem Assessment......................................................40

5.4 Lessons from the Japan Satoyama and Satoumi Assessment....................................................

6. KEY ISSUES IN DEVELOPING PRACTICAL GUIDANCE FOR SUCCESSFUL ECOSYSTEM

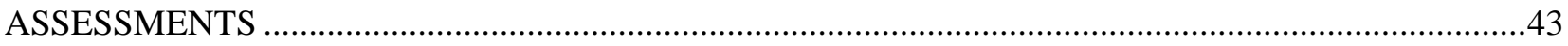

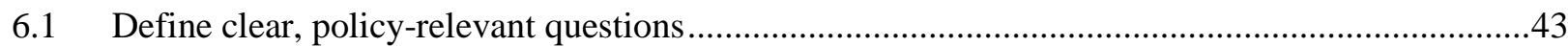

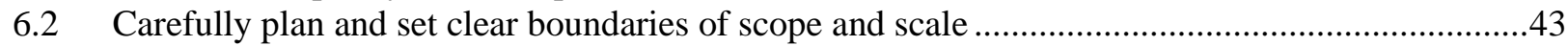

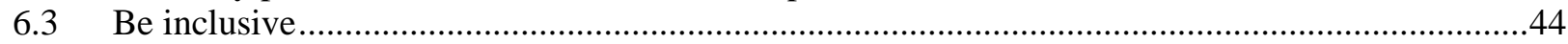

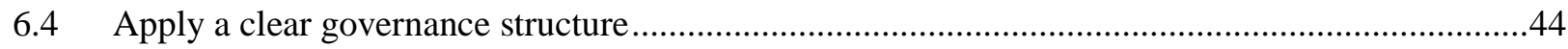

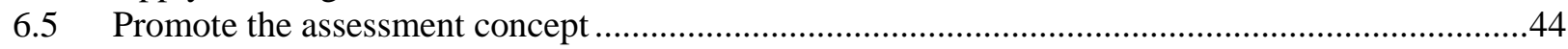

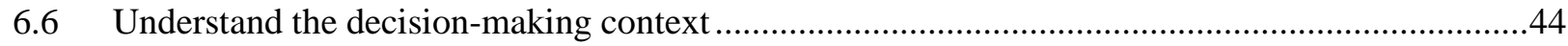

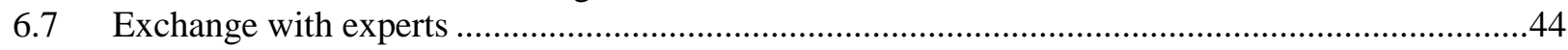

6.8 Appreciate the need to understand, use and present different types of information .....................45

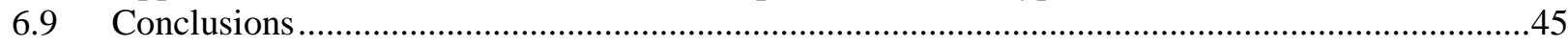

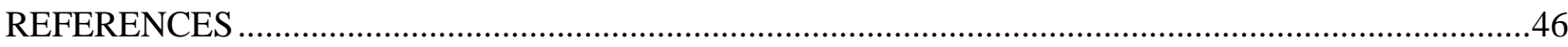

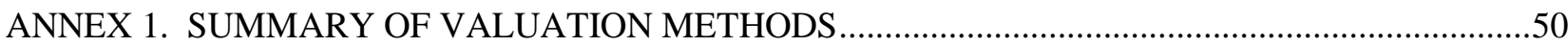




\section{Tables}

Table 1. Specific aspects to consider during the design stage of an ecosystem assessment.

\section{Figures}

Figure 1. The sub-global assessments from the Millennium Ecosystem Assessment .........................14

Figure 2. Ecosystem Assessment Framework ................................................................................17

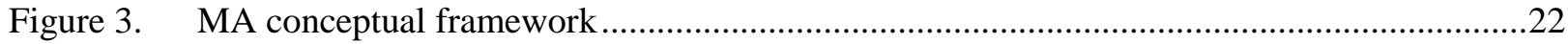

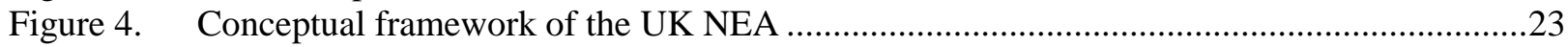

Figure 5. The full set of ecosystem process, services, goods/benefits and values used in the UK NEA25

Figure 6. Conceptual framework of the Japan Satoyama Satoumi Assessment (JSSA) ......................26

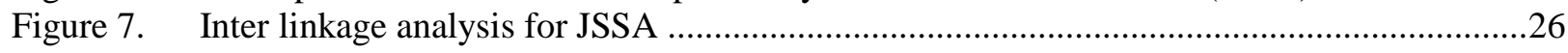

\section{Boxes}

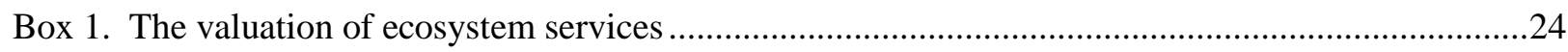

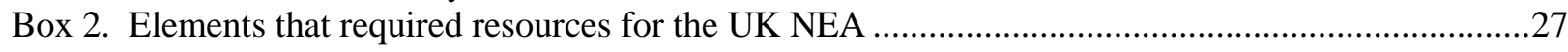

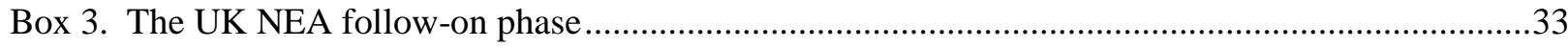




\section{ACRONYMS}

CICES Common International Classification of Ecosystem Services

Defra Department for Environment, Food and Rural Affairs

DPSIR Driver-Pressure-State-Impact-Response Framework

EU European Union

GDP Gross Domestic Product

IPBES Intergovernmental science-policy Platform on Biodiversity and Ecosystem Services

JSSA Japan Satoyama Satoumi Assessment

MA Millennium Ecosystem Assessment

MAES EU Working Group on Mapping and Assessment of Ecosystem Services

MS EU Member State

NBSAP National Biodiversity Strategy and Action Plan

NEA National Ecosystem Assessment

NEWP Natural Environment White Paper

NIA Nature Improvement Areas

OECD Organisation for Economic Cooperation and Development

PEI Poverty and Environment Initiative

ptMA Portugal Millennium Ecosystem Assessment

SGA Sub-global Assessment

TEEB The Economics of Ecosystems and Biodiversity

UK NEA UK National Ecosystem Assessment

UNDP United Nations Development Programme

UNEP United Nations Environment Programme

WTP Willingness to pay 


\section{EXECUTIVE SUMMARY}

Ecosystem services are the benefits people derive from ecosystems, including critical life-support functions, upon which our societies depend. Examples of ecosystem services include products such as food and water, regulation of floods, soil erosion and disease outbreaks, and non-material benefits such as recreational and spiritual benefits in natural areas. The term 'services' is usually used to encompass the tangible and intangible benefits that humans obtain from ecosystems, which are sometimes separated into 'goods' and 'services'. Ecosystem services and their benefits can be qualified and quantified through an ecosystem assessment. An ecosystem assessment is a social process through which the findings of science concerning the causes of ecosystem change, their consequences for human well-being, and management and policy options are brought to bear on the needs of decision-makers. The objective of this paper is to highlight the role such assessments play in informing policy-making, in particular information concerning the economic values of ecosystem services. Insights are drawn from National Ecosystem Assessments (NEAs) from the UK, Japan, Spain and Portugal; however, lessons learned come from a more comprehensive body of ecosystem assessments conducted at different geographical scales.

While this report examines the ecological and economic considerations around ecosystem management, it is important to recognise that in some policy settings (for example, fishery-dependent communities) the social aspects of ecosystem management can be extremely important for decision making. This paper recognises that assessments can involve many different tools such as the use of remote sensing and other spatial tools, scenarios, valuation and other policy tools, indicators and other metrics. This paper also $==$ focuses on the role economics plays in the policy impact of an NEA. In this context, several points deserve to be highlighted:

Ecosystem assessments are an example of integrated assessments and play an important role in synthesising and communicating complex information. They can both inform and influence decision-making processes

Ecosystem assessments are an example of integrated assessments as they look at processes leading to change, impacts of and responses to change. They focus on the concept of ecosystem services and therefore provide the connection between environmental issues and people, considering both the ecosystems from which services are derived and the people who depend on and are affected by changes in the supply of services. The Millennium Ecosystem Assessment (MA) has undoubtedly been fundamental in raising awareness of the potential role that ecosystem assessments can play in informing decisionmaking.

Ecosystem assessments can vary in geographical scale, from global to regional, to national and subnational. National Ecosystem Assessments (NEA) are most commonly initiated from two directions: those driven by policy and those driven by academic curiosity. Either way, the type of people leading the assessment, often experts from academia but also government officials, will be the same although the overarching governance might be different. It is worth noting that the source of an assessment's mandate can affect the overall success of the assessment in influencing decision-making. 
ENV/WKP(2014)9

\section{Based on current experience, some general challenges and considerations in national ecosystem assessment development have emerged}

Whilst each ecosystem assessment is unique in terms of the challenges that arise during the process, two high-level challenges relevant to any ecosystem assessment (regardless of scale) are: i) how to design a successful assessment; and ii) how to achieve impact within the decision-making process. The fundamental stages for undertaking an ecosystem assessment include exploration, design and implementation. Although some elements of the assessment process can be considered linear, it is important to note that others (such as communication, user engagement and building capacity) occur throughout the process and need to be considered at all stages.

Elements of an ecosystem assessment that need to be considered at the exploratory stage include determining the need for an assessment, determining stakeholder priorities, and defining the scope and boundaries of the assessment.

Ecosystem assessment design considerations include establishing a governance structure. This is critical to the successful management and implementation of an assessment but also in ensuring user engagement. Other design considerations include project planning including timescale and milestones, identifying key capacities, skills and resources required, and identifying the important ecosystems and ecosystem services, spatial scales of interest, temporal scales, data requirements and possible sources, and different knowledge systems. Agreeing key questions, developing a conceptual framework, planning a communication strategy and estimating the cost of conducting an ecosystem assessment are also essential in the development of an assessment.

During the implementation stage, peer review of the findings is a crucial stage of the assessment process. Development of the peer review process should be tailored to each assessment, reflecting its scale and context.

For an ecosystem assessment to achieve policy impact, three attributes are key to increasing the likelihood that the knowledge contained in an assessment will have influence. These are relevance, credibility, and legitimacy. Relevance refers to the ability of an assessment and its findings to address the particular concerns of a user. Legitimacy refers to the degree of political acceptability or perceived fairness of an assessment. Credibility refers to the perceived scientific and technical soundness of an assessment.

\section{Valuation of ecosystem services is an essential component of ecosystem assessments and can contribute towards better environment and development decision-making}

Ecosystem services have values for humans through the different benefits - economic, health and social - they provide for human well-being. Ecosystem services can be measured in monetary and nonmonetary terms. The underlying case for the valuation of ecosystem services in an ecosystem assessment is that it will contribute towards better decision-making by ensuring that policy appraisals fully take into account the costs and benefits to the natural environment and by highlighting much more clearly the implications for human well-being while providing policy development with new insights.

Undertaking a valuation exercise of ecosystem services involves three steps: 1) assessing the impact of small (direct and indirect) changes in ecosystems on the flow of ecosystem services, 2) quantifying how the provision of ecosystem-related goods is affected by changes in ecosystem services; and 3) measuring the resulting change in human well-being. The type of valuation technique (e.g. direct market valuation, revealed preference methods, stated preference methods, benefit transfer methods) chosen will depend on the type of ecosystem service to be valued, as well as the quantity and quality of data available. 
Demonstrating the monetary values of ecosystem services allows policy-makers to raise awareness of their importance and to mainstream them into decision making by bringing them to the same level as other financial benefits. Building on the Millennium Ecosystem Assessment and The Economics of Ecosystems and Biodiversity (TEEB) initiative, numerous TEEB national studies are currently underway in countries around the world to assess, map and value ecosystem services at national and local levels.

\section{There is evidence that national ecosystem assessments can and are informing policy decisions}

Ecosystem assessments have policy impacts at local, national, regional and international level. For example, NEAs conducted in the UK and Japan have been referred to in documents setting out future policy or biodiversity strategies or legal documents setting out nature management and conservation. Developing an assessment with careful consideration of the wider policy context in which the findings can be used to inform a number of priorities, increases the likelihood that an assessment has a more significant policy impact. In addition, ensuring that an assessment has the correct authorising environment, engaging stakeholders throughout the process as well as considering the timing of the release of findings have all been found to influence the policy impact of an NEA. The newly-established Intergovernmental sciencepolicy Platform on Biodiversity and Ecosystem Services (IPBES) and initiatives such as the TEEB Coalition have the potential to increase the influence of assessments on policy and decision-making at broader geographical scales. Guidance released around the revision of National Biodiversity Strategies and Action Plans (NBSAPs), highlights the value of NEAs in providing the evidence base for actions. It is worth noting that the policy impact of global assessments is not often assessed and if it is, the process can be difficult, and the true policy impact not known for many years following the completion of the assessment. Future NEAs should be encouraged to determine early in the process how policy impact will be accessed.

Valuable lessons to inform future practitioners who lead NEAs and enhance the overall efficiency and success of subsequent assessments can be drawn from national, as well as regional and global scale assessments

Emerging general lessons from completed NEAs (e.g. UK, Portugal, Spain and Japan) pertain to, among other things, the policy impact of assessments, availability of data and relevant advice, establishment of a strong governance structure, assessment team familiarisation, stakeholder engagement, management and communication, scale of which assessments carried out and adequate budget and human resources. It is evident that, despite regional variations in scope and objectives, many of these lessons are similar between the different assessments.

Despite the complexity and diversity of ecosystem assessments, common lessons are emerging, and a series of practical guidance points for successful ecosystem assessments can be drawn from them

The development of a concise guidance document, highlighting a stage-by-stage process by which to implement these lessons is a challenging task, as each national ecosystem assessment is unique, with outputs inexorably linked to the scale and location in question. Ecosystem assessments are iterative in nature: as an assessment plays out, new discoveries will be made that need to be fed back into the process. However, underlying themes can be extracted from the lessons learned by each NEA examined in the paper and have also been reflected by a wide range of assessment practitioners through the Sub-Global Assessment Network. Good practice lessons and insights for a successful assessment, derived from this analysis, include the need to:

1. Define clear, policy-relevant questions

2. Carefully plan and set clear boundaries of scope and scale 
ENV/WKP(2014)9

3. Be inclusive

4. Apply a clear governance structure

5. Promote the assessment concept

6. Understand the decision-making context

7. Exchange with experts

8. Appreciate the need to understand, use and present different types of information

These elements are largely process-orientated, focusing on securing buy-in, gaining political will and operationalising scientific results. Almost every lesson identified relates back to buy-in, and creating an ethos of openness, communication and shared learning across diverse groups. This is not only something that needs to be sought at the beginning through 'promoting' the assessment, but also through seizing opportunities that arise for generating trust, ownership and mutual understanding as the process unfolds. What is more, without this buy-in, there will be little uptake of results in the communication and outreach stages. Space for learning together and learning by doing is critical if the assessment results and policy options are to be operationalised. This allows the development of practical implementation tools which build upon existing institutions. Assessment practitioners need to work as closely as possible with existing models, incorporating incremental change, to promote a fairer more sustainable societal system, one which works for the people, and sustains human well-being within the ecological limits of the biosphere. 


\section{INTRODUCTION}

People everywhere depend on ecosystems for their well-being. The services provided by ecosystems range from those easily recognised such as provision of food and timber, to those less recognised such as flood protection, carbon sequestration and spiritual benefits. These services collectively support human well-being and allow for the achievement of long-term development goals. The findings of the 2005 Millennium Ecosystem Assessment (MA) ${ }^{1}$, including several sub-global assessments (SGAs) confirmed the increasingly important contributions of ecosystem services to human well-being.

Ecosystem services based approaches, including ecosystem valuation, are crucial to tailor environment and development strategies to countries' physical and ecological conditions, and are essential to integrate the local and global concerns into sector-specific decision-making processes. Since the MA, the number of National Ecosystem Assessments (NEAs) has increased considerably, creating a significant body of experiences, methods and processes. Countries such as the UK, Spain, Japan and Portugal have completed the first phase of their assessments, while other countries including France, Israel and Finland are in the early stages of designing and conducting their assessments. There are also a number of TEEB studies that are in the scoping stage, such as Georgia ${ }^{2}$. To assist other countries to successfully undertake a National Ecosystem Assessment (such as the UK NEA) ${ }^{3}$, to allow their national policy makers to understand the value of their nation's natural capital, there is a need to pool recent experiences and lessons learned.

This report aims to draw insights from experience in different countries of the added value to policy making of undertaking national level ecosystem assessments. Insights are derived from a number of national ecosystem assessments, in particular the UK NEA as this is the most comprehensive NEA in terms of coverage to date. The report is organised as followed. Section 2 briefly describes what an ecosystem assessment is, including reasons for conducting an assessment and entities or stakeholders involved in conducting one. Section 3 outlines some of the challenges and considerations involved in NEA development. Section 4 highlights policy impacts of national ecosystem assessments at different scales (i.e. local, national, regional and international) while Section 5 reviews lessons learned. Section 6 concludes with practical guidance for successful ecosystem assessments and highlights key insights on the role of NEA's in influencing policy making.

\footnotetext{
${ }^{1}$ http://www.unep.org/maweb/en/index.aspx

${ }^{2}$ National TEEB studies will often focus on a particular policy issue, but will however relay on much of the information generated by an ecosystem assessment, which has a broader focus. Guidance on undertaking a national TEEB study can be found at www.unep.org/pdf/TEEB_GuidanceManual_2013.pdf

${ }^{3}$ http://uknea.unep-wcmc.org/
} 
ENV/WKP(2014)9

\section{WHAT IS AN ECOSYSTEM ASSESSMENT?}

An assessment process "brings together diverse strands of knowledge in a way that is useful for decision making" (UNEP/GC.25/INF/12). An ecosystem assessment analyses existing data and information on ecosystems and ecosystem services. It does not generally undertake new primary research but applies expert judgement to knowledge that has been generated by the scientific community to provide credible answers to policy-relevant questions (Ash et al. 2010).

There are many different types of assessments which can be broadly divided into four categories: process, impact, response, integrated (UNEP/GC.25/INF/12). Ecosystem assessments are examples of integrated assessments as they look at processes leading to change, impacts of and responses to change. An ecosystem assessment can be defined as "a social process through which the findings of science concerning the causes of ecosystem change, their consequences for human well-being, and management and policy options are brought to bear on the needs of decision-makers." (MA 2005). Ecosystem assessments, focus on the concept of ecosystem services ${ }^{4}$, and therefore "provide the connection between environmental issues and people, considering both the ecosystems from which services are derived and the people who depend on and are affected by changes in the supply of services"(Ash et al. 2010). Other assessment typologies which consider ecosystems do exist, such as the State of the Environment-type assessments, but these are not discussed in this paper.

The MA has been fundamental in raising awareness of the potential role that ecosystem assessments can play in informing decision-making. Published in 2005, the MA covered current state and trends, scenarios, policy responses and multi-scale assessments. In addition to a general synthesis report, reports were produced on biodiversity, desertification, opportunities and challenges for business and industry, wetlands and water, and health (MA 2005). The conceptual framework of the MA has been adapted to suit the needs of a number of sub-global assessments including the UK National Ecosystem Assessment. Furthermore, the MA conceptual framework has informed other assessments such as The Economics of Ecosystems and Biodiversity (TEEB) (IPBES/1/INF/8).

Ecosystem assessments can vary in geographical scale, from global to regional, to national and subnational (IPBES/1/INF/8). The MA was a multi-scale assessment, integrating a total of 36 assessments conducted at different and diverse scales into one overarching, global assessment (see Figure 1). Regional level assessments included those in the Altai-Sayan, Caribbean Sea, Central Asia mountain ecosystems and Southern Africa; national level assessments included those from Fiji, Papua New Guinea and Portugal, while sub-national assessments included those in the northern Australian floodplains, coastal British Columbia, the Glomma River basin of Norway, and Alaska and Wisconsin in the United States of America. In addition, two topical assessments (alternatives to slash-and-burn; and trade, poverty and environment) assessed multiple sites in South America and Asia, and Africa, Asia and Latin America respectively (MA 2005).

\footnotetext{
${ }^{4}$ The benefits people obtain from ecosystems that contribute to making human life both possible and worth living (MA 2005).
} 
Figure 1. The sub-global assessments from the Millennium Ecosystem Assessment

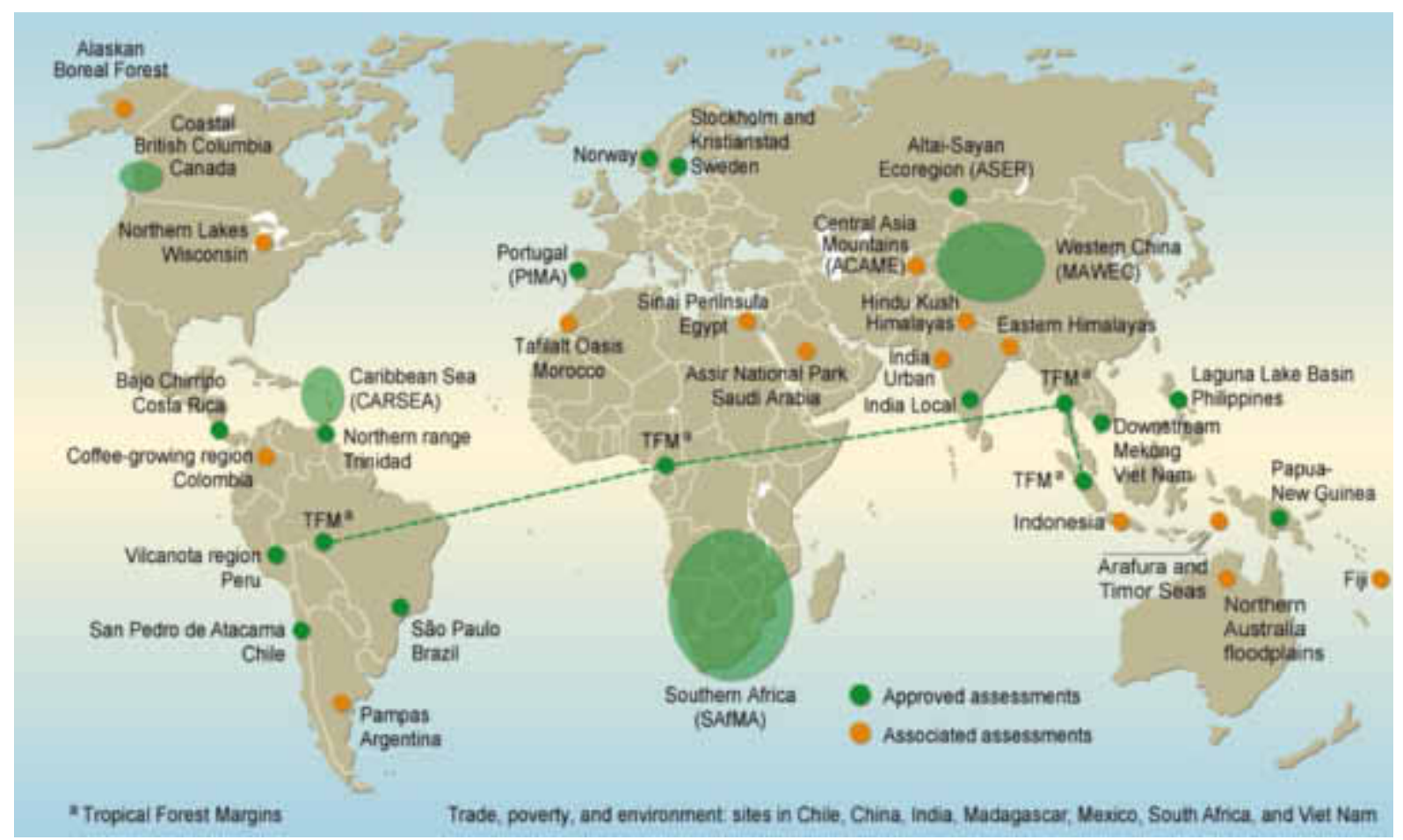

Source: MA 2005.

\subsection{Why conduct an ecosystem assessment?}

An ecosystem assessment plays an important role in synthesising and communicating complex information and can both inform and influence decision-making processes (Ash et al. 2010). For example, Ash et al. (2010) identified that ecosystem assessments can:

- Respond to decision makers' need for credible and robust information.

- Highlight trade-offs between decision options.

- Model future prospects to avoid unforeseen, long-term consequences.

- Provide critical judgement of options and uncertainty enabling decision makers to choose policies that sustain the appropriate mix of services ${ }^{5}$.

- Improve the way benefits of ecosystem services are described and valued, thereby increasing decision makers' understanding of how their actions might change these services.

\footnotetext{
${ }^{5}$ This point raises the issue of the science-policy boundary and to what extent countries may or may not wish their NEAs to be policy prescriptive. Experience to date has shown that in the majority of cases it is most effective to present findings that are policy relevant but not policy prescriptive as the choice among policy options is never a strictly scientific one.
} 
- Help to build a bridge between development and environmental communities by increasing awareness of the links between ecosystem management and the attainment of economic and social goals.

- Uncover and bring together a fragmented evidence base, and test out different data sets so that they can be better used together in the future (e.g., house prices and environmental factors).

\subsection{Who conducts an ecosystem assessment?}

NEAs are most commonly initiated from two directions: those driven by policy and those driven by academic endeavours to develop the knowledge-base. Either way, the type of people leading the assessment, often experts from academia but could be government officials, will be the same although the overarching governance might be different (see Section 3.1.2.1 for more details on governance).

The UK NEA is an example of a government-driven assessment, as it was commissioned in response to the findings of the MA in 2005, which demonstrated that at the global scale many ecosystem services are being degraded or even lost. The UK House of Commons Environmental Audit Committee subsequently recommended that "the Government should conduct a full MA-type assessment for the UK to enable the identification and development of effective policy responses to ecosystem service degradation" (House of Commons Environmental Audit 2007).

In comparison, the Portugal Millennium Ecosystem Assessment (ptMA) had no formal mandate. However stakeholders, representing national and local government, non-governmental organisations, private sector, and local development organisations, actively participated in designing and defining the scope of the assessment via a User Needs and Response Options Report (IPBES Catalogue of Assessments 2012a).

The source of an assessment's mandate can affect the overall success of the assessment in influencing decision-making. Section 3 provides more detail on the authorising environment and legitimacy of an assessment. 


\section{CHALLENGES AND CONSIDERATIONS IN NATIONAL ECOSYSTEM ASSESSMENT DEVELOPMENT}

Whilst each ecosystem assessment will be unique in terms of the issues that arise during the process, two high level issues relevant to any ecosystem assessment (regardless of scale) are: i) how to design a successful assessment; and ii) how to achieve impact within the decision-making process. Considerations in order to best address these two issues are discussed below in the context of national level assessments.

\subsection{Designing a successful assessment}

The design of an ecosystem assessment needs to be considered carefully if it is to achieve its objectives and have the desired impact on policy and decision making. Ash et al. (2010) identified three fundamental stages for undertaking an ecosystem assessment: exploratory, design and implementation (see Figure 2). Although some elements of the assessment process can be considered linear, it is important to note that others (such as communication, user engagement and building capacity) occur throughout the process and need to be considered at all stages.

Elements of an ecosystem assessment that need to be considered at each stage are outlined below. Detailed information on the practicalities of undertaking an ecosystem assessment are described in Ecosystems and Human Well-being: A Manual for Assessment Practitioners (Ash et al. 2010). A further useful resource is An Assessment of Assessments (UNEP and IOC-UNESCO 2009) which identifies best practices for twelve design features to facilitate an influential assessment. This report analyses practices and approaches from marine and coastal assessments but its findings are equally applicable to assessments in general.

\subsubsection{Exploratory stage}

In the exploratory, or scoping, stage elements for consideration include determining both the need for an assessment and the many stakeholders' priorities, together with the assessment's scope and boundaries. Completion of this stage will help in exploring what will need to be included in the budget but it is not until completion of the second stage, on design, that a more precise idea of the potential budget needed can be ascertained.

\subsubsection{Determining the need for an assessment}

As part of the exploratory stage it is of strategic importance to i) develop the specific objectives of the assessment according to what is feasible and possible, thereby keeping expectations realistic, and ii) identify what is needed in order to generate/harness as much support as possible from potential stakeholders (Ash et al. 2010). The rationale of the assessment should be discussed with a wide range of stakeholders - both users of the ecosystems and of the assessment results - so they may voice their perspectives and interests, which may be substantially diverse, and possibly conflicting. 
It is also important that information is promoted in a way that is both understandable and indicates the potential value of undertaking an assessment (Ash et al. 2010). This leads to a demand driven approach and highlights relevance, both of which will influence the impact an assessment could have.

\section{Figure 2. Ecosystem Assessment Framework}

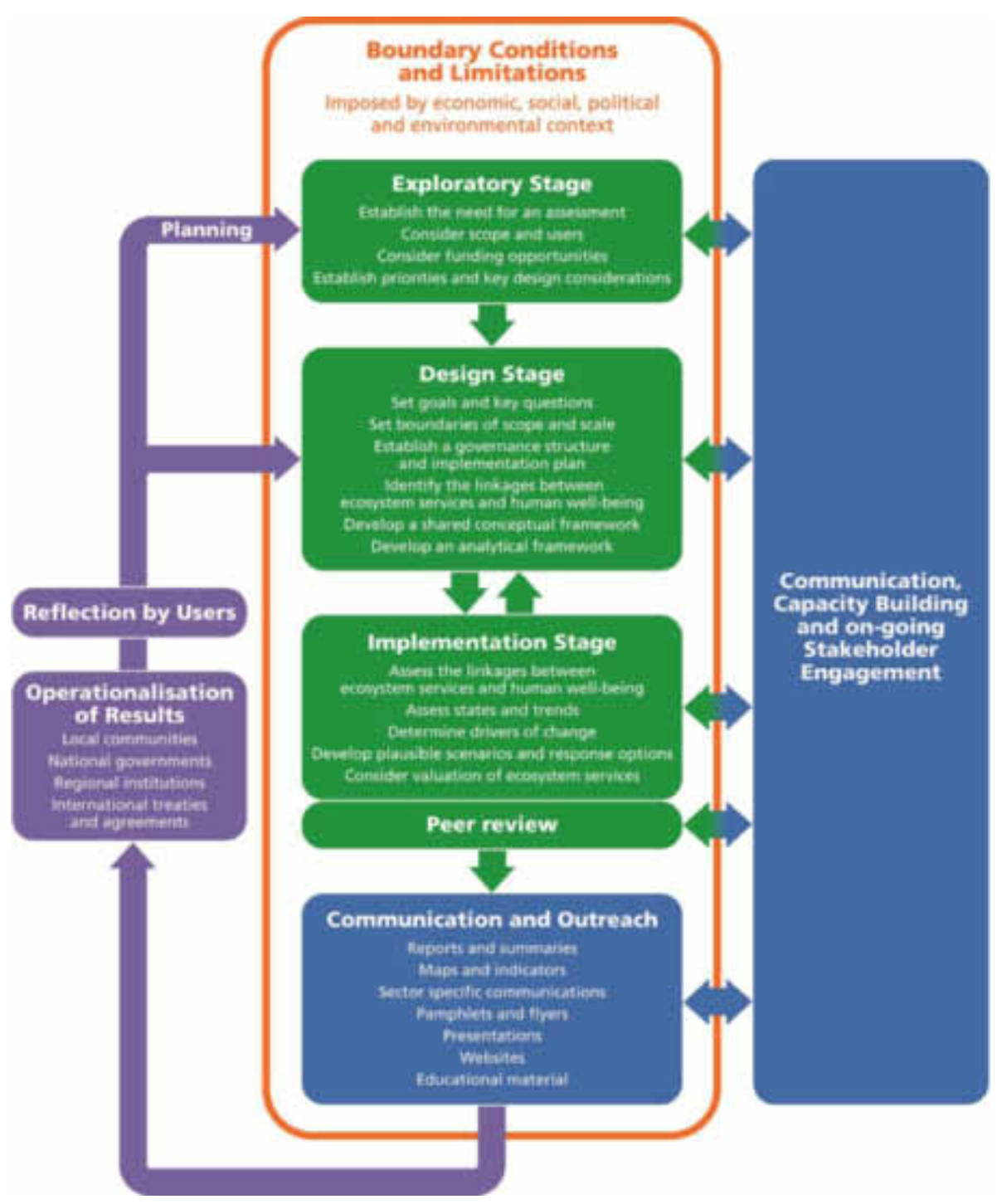

Source: SGA Network 2012a, adapted from the Millennium Ecosystem Assessment.

As noted, the UK NEA was a government-driven assessment as the need was recognised by the UK House of Commons Audit Committee. In addition to funding from the Department for Environment, Food and Rural Affairs (Defra) and the Devolved Administrations, two research councils also recognised the value of conducting an assessment of the benefits of the UK's natural environment to the economy and society. Identifying gaps in the evidence base is one outcome of undertaking an assessment and can assist in guiding future research agendas. 
Providing the opportunity for the different disciplines (e.g., social scientists, economists, natural scientists) that would be involved in an assessment to convene in the exploratory stage and learn about and understand each other's needs and language is also important. The UK NEA did not do this until the design stage and consequently faced some challenges in finding a common language between disciplines.

\subsubsection{Determining stakeholder priorities}

The suggested process of undertaking an ecosystem assessment allows practitioners to engage with and inform decision makers and stakeholders at each stage of the process (even before any results are produced) thereby enhancing the potential impact of the assessment. A User Needs assessment at the beginning of the process is a good way to initiate stakeholder engagement and will feed into an overall engagement strategy. Such a survey would result in a list of interested parties and the type of information on ecosystem services that they need, which will help to identify who the key users are (Ash et al. 2010).

In the case of the UK NEA, Defra (the principal funder) conducted a stakeholder consultation on the proposed approach to the National Ecosystem Assessment for England. Stakeholders were asked to suggest data sources including known gaps; suitable case studies; recommendations for selection to the Expert Panel and User Group; and any linked initiatives that could feed into or benefit from the outputs of the assessment.

Various aspects of stakeholder participation in the assessment process, such as which stakeholders should be involved, how they are involved in a meaningful way and at which stage of the assessment, all requires careful consideration. Although stakeholder participation can yield significant benefits, if the approach is not well thought out there is a risk that an assessment's goals and influence may be undermined (UNEP and IOC-UNESCO 2009).

\subsubsection{Defining scope and boundaries}

Linked to the above considerations, the scope and boundary of an NEA will determine the principal stakeholders. The geographic scale may seem obvious when considering a national scale assessment but in the case of the UK NEA a scoping study was initially conducted for England only (Haines-Young et al. 2008). It was decided that the scope of the assessment would be expanded to be fully national and to include Wales, Scotland and Northern Ireland on recommendation of the scoping study that this would be of greater value to decision-making. The study also recognised the nature of some ecosystem services in that they flow over political boundaries. This makes identifying the beneficiaries of goods and services, as well as the management of these benefits, more complex.

Determining the external physical boundaries of an assessment includes considering whether or not to include offshore islands. The UK has many offshore islands; the main islands were included in the mapping and in some analyses of the UK NEA where data was available. In an assessment, inclusion of offshore islands can depend on resources and data availability.

A further consideration of the UK assessment was whether to include British Overseas Territories. The decision was taken not to include them both on the grounds that their ecosystems are quite distinct from the mainland ecologically, but also that their governance and therefore policy needs are different and therefore different types of assessments might be more appropriate for them.

Another issue that merits consideration is to determine the need for building capacity for a longerterm, sustained assessment (i.e. repeated assessments over time). A key component to the ongoing US National Climate Assessment, for example, is the sustained assessment process which intends to 
facilitate the continuous and transparent participation of scientists and stakeholders across regions and sectors, enabling new information and insights to be synthesised as they emerge ${ }^{6}$

Ecosystem assessments can vary in thematic scope (how many policy issues the assessment process will address) and the empirical detail (the resolution at which the outputs from the assessment are compiled and presented). Haines-Young et al. (2008) identified four designs which reflect a mixture of these options:

- Broad and shallow - A cross-sectoral, single level assessment

- $\quad$ Narrow and deep - A targeted, multi-level assessment

- Narrow and shallow - A targeted, single level assessment

- Broad and deep - A cross-sectoral, multi-level assessment

The design option chosen can depend on resources available and whether there are any time constraints on delivering an assessment.

\subsubsection{Design stage}

On completion of the exploratory stage and having determined the feasibility of undertaking a national scale assessment there are a number of design considerations. These inform the analytical approach used, the development of a conceptual framework, composition of the assessment team, and the budget. In addition, these discussions early on will help to determine clearly defined and realistic objectives, which will guide the process and provide a basis for evaluating achievements (UNEP and IOCUNESCO 2009).

\subsubsection{Establishing a governance structure}

Establishing a governance structure is critical to the successful management and implementation of an assessment but also in ensuring user engagement. A governance structure clarifies the roles and responsibility of different groups, thereby providing a sense of ownership to the process, and can ensure legitimacy and credibility.

In the case of the UK NEA for example, the governance consisted of multiple different groups, with a specific purpose. An Expert Panel provided scientific expertise and guidance to the process, from agreeing on a conceptual framework to peer-reviewing outputs. The intellectual leadership of the Expert Panel was provided by the Co-Chairs. A Client Group (i.e. the funders) monitored and agreed the resources for the assessment while also ensuring the relevance of the assessment for decision-makers. A User Group (i.e. the stakeholders) was put into place to ensure the outputs were useful and would meet the needs of end users of the assessment. Coordinating Lead Authors with author teams led the analysis of information. And a Secretariat coordinated the assessment process and individual activities.

The Portuguese Millennium Ecosystem Assessment (ptMA) had a Steering Committee, an Advisory Board, a Science Team and a group of Users. The Advisory Board, who advised the Steering Committee on the conduct of the assessment and coordinated the process of the pilot and final assessment, was composed of a mixture of representatives from the other governance groups including the research team and Users team as well as by others scientists and stakeholders. The Users represented different sectors, including national and local government, non-governmental organisations, agriculture and industry.

\footnotetext{
${ }^{6}$ For further information see http://www.globalchange.gov/engage/activities-products/sustained-assessment
} 
Similar to the UK NEA they were the main users of the information that was produced and major stakeholders of the ecosystems being assessed.

The governance structure for the Japan Satoyama Satoumi Assessment (JSSA) consisted of:

- A Board: represented key users (e.g. local governments, academia and non-governmental organizations) who governed the assessment process by providing direction and input from their representing institutions, endorsing the outcome, facilitating capacity building needed by users, and feeding the outcome back into their institutions and beyond.

- A Governmental Advisory Committee: co-chaired by a natural and social scientist, this group composed of government officials representing relevant ministries and agencies at the national level, and associated with the Board to further facilitate involvement and commitment to the process by different national governmental agencies.

- Science Assessment Panel: natural and social scientists oversaw the technical execution of the assessment work to ensure the scientific credibility and accuracy of the information generated from the assessment.

- Cluster Working Groups: organised in accordance with a number of clusters into which different assessment sites were grouped on the basis of ecological-climate and socio-economic variables, and composed of local scientists and experts who undertook the cluster assessment work.

- National Working Group: composed of scientists and experts who undertook the assessment work on the national scale by integrating and synthesizing the outputs from the cluster assessments.

- Review Panel: an independent body involving external reviewers who provided peer-review comments and ensured that all review comments were adequately handled and responded by the authors.

- Secretariat: served to manage logistical, administrative, and technical support for the assessment.

The examples above show that the titles given to the various groups vary between assessments, depending on size and scope of the assessment. Nevertheless they are similar in that they include i) a diverse range of stakeholders which represent the community at large and can provide information about user needs, as well as ii) technical expertise to ensure the assessment process is fair and balanced and can provide advice on complex or contentious issues (Ash et al. 2010).

\subsubsection{Other design considerations}

Each ecosystem assessment needs to be tailored to fit its context and requirements. Table 1 outlines a number of other design considerations (Ash et al. 2010). 
Table 1. Specific aspects to consider during the design stage of an ecosystem assessment

\begin{tabular}{|l|l|}
\hline Consideration & Rationale \\
\hline $\begin{array}{l}\text { Project plan including } \\
\text { timescale and milestones }\end{array}$ & $\begin{array}{l}\text { As with all projects, successful project management requires a well thought out project plan. } \\
\text { Timescale will be influenced by the resources available but may also be determined by key } \\
\text { political events. }\end{array}$ \\
\hline $\begin{array}{l}\text { Identifying key } \\
\text { capacities/skills and } \\
\text { resources required }\end{array}$ & $\begin{array}{l}\text { This is important for building the assessment team and governance structure. For example, } \\
\text { additional skills required by include GIS experience, science writing and graphic design. }\end{array}$ \\
\hline $\begin{array}{l}\text { Identifying the important } \\
\text { ecosystems and ecosystem } \\
\text { services }\end{array}$ & $\begin{array}{l}\text { How to classify ecosystems can depend on the data available. Determining which ecosystem } \\
\text { services to focus on is important if resources are limited and should reflect the objectives of the } \\
\text { assessment. These considerations are important for both the conceptual framework and the } \\
\text { analytical approach. }\end{array}$ \\
\hline Spatial scales of interest & $\begin{array}{l}\text { National Ecosystem Assessments can be conducted at multiple scales if it is policy relevant. See } \\
\text { f.2.1 for details on the UK NEA. Spatial scale is important for developing the conceptual } \\
\text { framework. }\end{array}$ \\
\hline Temporal scales & $\begin{array}{l}\text { The status and trends component of the assessment will look backwards while the scenarios } \\
\text { component will look forward. Determining the temporal scale is important for designing the } \\
\text { analytical approach and data requirements. }\end{array}$ \\
\hline $\begin{array}{l}\text { Data requirements and } \\
\text { possible sources }\end{array}$ & $\begin{array}{l}\text { Determines the feasibility of which ecosystems and ecosystem services can be assessed and at } \\
\text { which temporal scales. }\end{array}$ \\
\hline $\begin{array}{l}\text { Different knowledge } \\
\text { systems }\end{array}$ & $\begin{array}{l}\text { Scientists and policy makers recognise that new assessment processes need to become robust } \\
\text { enough to accommodate and value different knowledge systems (local, traditional or indigenous) } \\
\text { in addition to scientific knowledge. Due to the social composition of the UK it was not felt } \\
\text { necessary to consider these different systems. }\end{array}$ \\
\hline
\end{tabular}

\subsubsection{Agreeing key questions}

Key questions define (and constrain) the direction or scope of an assessment. These should be both clear and policy relevant, and based on how an assessment results are going to be used and incorporated into decision-making processes in the context of the scale of the assessment. Stakeholders including end users should be consulted during the development of the key questions.

In the UK NEA, key questions were drafted by the Secretariat which were then discussed in a combined meeting of the governance groups (Expert Panel, Co-Chairs, User Group, Client Group, Secretariat) before being agreed by the Client Group.

In the JSSA, key questions drafted under the guidance of the co-chairs of the Board and the Science Assessment Panel were first circulated among the users/stakeholders. Incorporating some feedback from the users/stakeholders, those questions were re-examined and rephrased by the Science Assessment Panel and later by the Board. During the course of the assessment work, the questions were modified and rephrased, which were then discussed and approved by the Board and Governmental Advisory Committee.

The Spanish NEA defined the direction of their assessment by developing key questions based around two main objectives: (i) at the national level, to provide information for the implementation of the National Strategies and Action Plans (NBSAPs) for Biodiversity and Natural Heritage 2011-2017 and (ii) to link with the European level biodiversity targets (Target 2, Action 5) of the Biodiversity strategy based on existing similar questions from other national assessments (i.e. UK NEA). 


\subsubsection{Developing a Conceptual Framework}

A conceptual framework provides a logical structure for evaluating systems by representing the main components of a system or issue of interest and helps to guide the assessment. It allows practitioners to work within the same boundaries while promoting a common understanding of what is being assessed (Ash et al. 2010). In addition, a conceptual framework illustrates the link between different components - in the case of an ecosystem assessment this includes ecosystem services and human well-being. The drivers of change component of the conceptual framework identifies the implications of human activities on ecosystems and ecosystem services (e.g. the environment-economy linkages).

Figure 3. MA conceptual framework

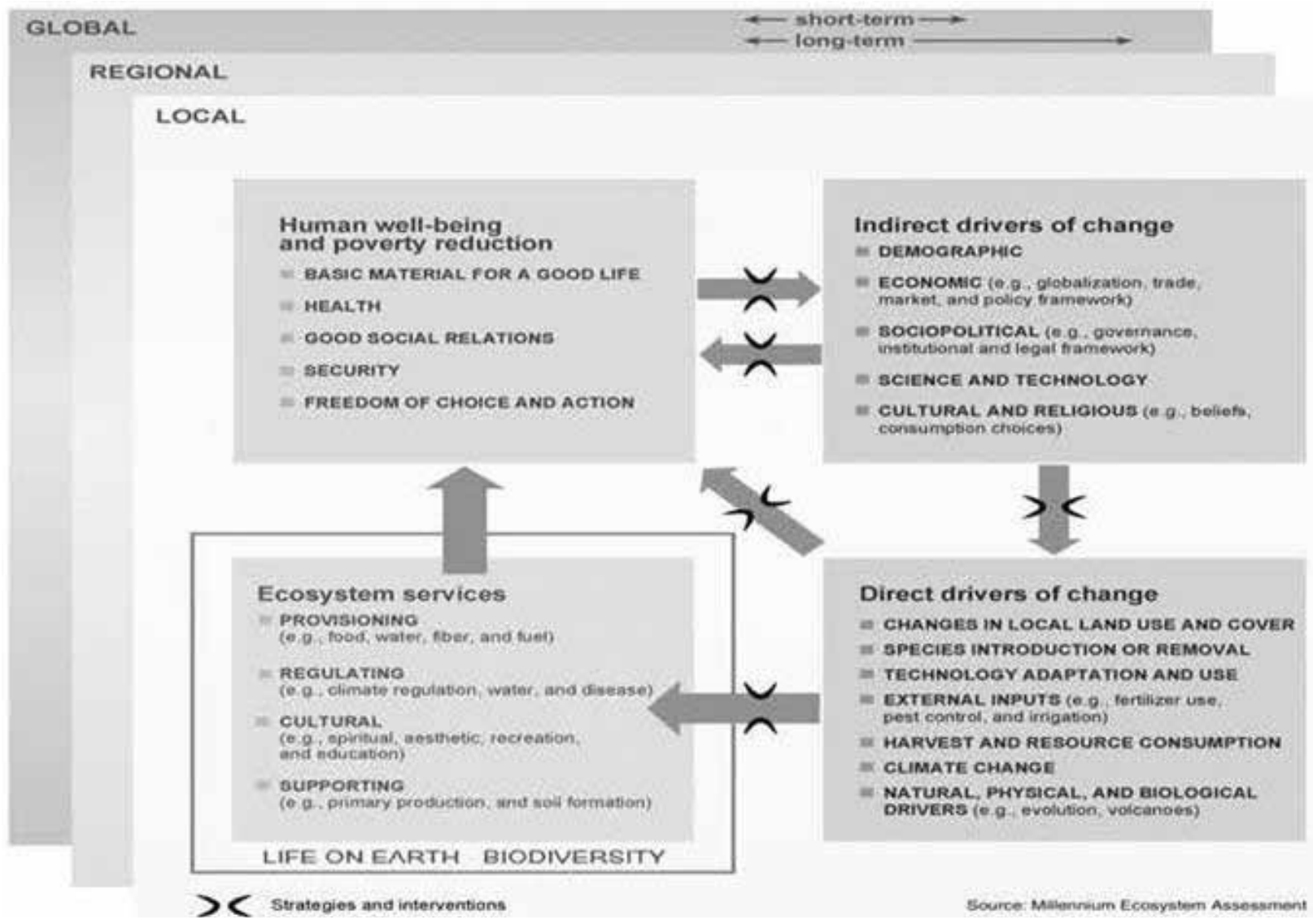

Source: MA 2005. 
The UK NEA built on the MA's conceptual framework (see Figure 3) and incorporated developments in theory and practice (see Figure 4):

- In the economic valuation, 'final ecosystem services' were distinguished from services which are part of a suite of ecosystem processes to avoid double counting. In addition 'goods' were identified, defined as the outcome of final ecosystem services which people value (see Box 1 and Figure 5).

- Non-monetary values of both health and shared social value were recognised so they might be considered alongside economic value.

- The way biodiversity is treated was slightly different from the MA as its role in underpinning natural processes, which depends on biodiversity from landscapes, seascapes, habitats and wild species, was explicitly separated out (UK NEA 2011).

Figure 4. Conceptual framework of the UK NEA

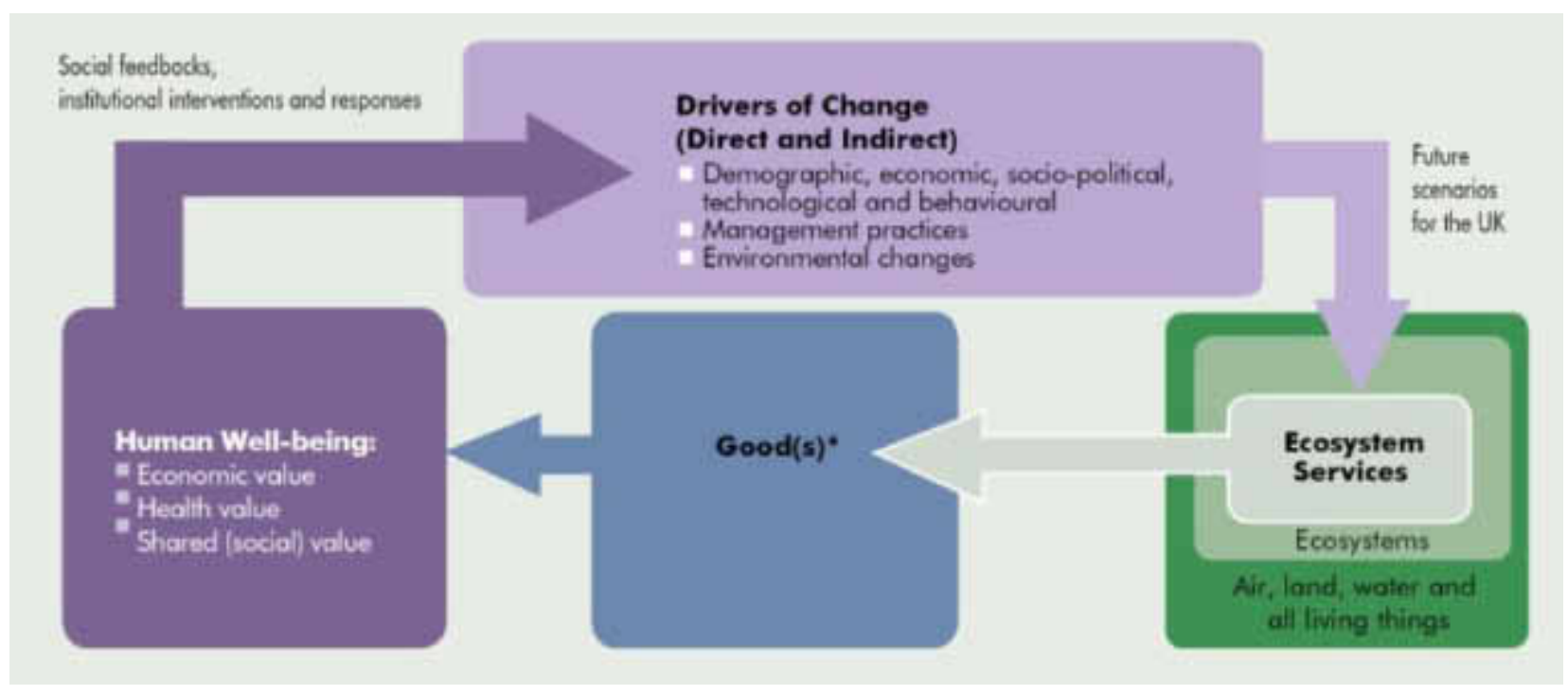

Source: UK NEA 2011. 


\section{Box 1. The valuation of ecosystem services}

Ecosystem services provide significant benefits to society through their contribution to human well-being (MA 2005; TEEB 2010; Bateman et al. 2011a, OECD 2012). Valuation can be defined as the process of assessing the contribution of ecosystem services or goods (i.e. biodiversity, flood protection, recreational opportunity) to meeting human goals, and expressing this in an economic value (Farber S. et al. 2002).

The underlying case for the valuation of ecosystem services is that it will contribute towards better decisionmaking by ensuring that policy appraisals fully take into account the costs and benefits to the natural environment and by clearly highlighting the implications for human well-being. Although the importance of ecosystem services can be measured in monetary and non-monetary terms, there are an increasing number of studies measuring these values in monetary terms (de Groot et al. 2010).

Ecosystem services have values for humans through the different benefits they provide for human well-being And the UK NEA defined these as: (i) economic benefits through their contribution to the production of goods and services; (ii) health benefits through their contribution to physical, mental and social (individual) well-being); and (iii) social benefits through their contribution to shared, collective socio-cultural norms and traditions .

These benefits represent different value types for humans (OECD 2002, TEEB 2010): (i) Direct use values relate to human consumptive (e.g. crops, fiber, water, etc) and non-consumptive use of ecosystems (recreation, spiritual and cultural well-being); (ii) Indirect use values arise, for example, from water regulation and purification, pollination, nutrient cycling and soil fertility; (iii) Non-use values result from the satisfaction from the mere existence of ecosystem services and from knowing that other people or future generations benefit from ecosystem services; and (iv) option values are linked to future use or non-use values.

Economists have applied a number of well-established methods in order to value ecosystem services (e.g. Pascual and Murradian 2010; Turner et al. 2010; Bateman et al. 2011a, OECD 2002). These can be broadly categorised as market-based valuation, revealed and stated preference methods

The type of valuation technique chosen will depend on the type of ecosystem service to be valued, as well as the quantity and quality of data available. Some valuation methods may be more suited to capturing the values of particular ecosystem services than others. These methods are outlined in Annex 1. Examples of where valuation have been used in national studies are summarised below.

\begin{tabular}{|c|c|}
\hline Scandinavia & $\begin{array}{l}\text { A Nordic TEEB local project "Natural Growth" was initiated in 2011; three municipalities in Sweden, } \\
\text { Denmark and Finland are applying the TEEB methodology to a scoping assessment of the socio- } \\
\text { economic significance of biodiversity and ecosystem services and their integration into decision-making } \\
\text { processes (TEEB 2011). }\end{array}$ \\
\hline The Netherlands & $\begin{array}{l}\text { A national TEEB study has been started in 2012. It is focused on regional, city, and overseas cases, trade } \\
\text { flow impacts on ecosystem services abroad, business dependencies on ecosystem services and the } \\
\text { processing of new national policy cases (TEEB 2011). }\end{array}$ \\
\hline Germany & $\begin{array}{l}\text { A series of TEEB thematic reports on biodiversity and climate, rural areas, green infrastructure in cities, } \\
\text { and innovative instruments are being carried out in Germany between } 2012 \text { and } 2015 \text { (TEEB 2011). }\end{array}$ \\
\hline $\begin{array}{l}\text { The Association } \\
\text { of Southeast } \\
\text { Asian Nations }\end{array}$ & $\begin{array}{l}\text { Between } 2011 \text { and 2012, countries forming the Association of Southeast Asian Nations conducted policy } \\
\text { dialogues and training workshops to raise awareness and build capacity, as part of a project called } \\
\text { "Disseminating the Values of Ecosystems and Biodiversity to Enhance Climate Change and Biodiversity } \\
\text { Strategies in Southeast Asia". }\end{array}$ \\
\hline Tunisia & $\begin{array}{l}\text { Tunisia has completed an economic valuation of the country's forest ecosystem goods and services with } \\
\text { the aim to integrate the value of biodiversity and ecosystem services in to national accounting. }\end{array}$ \\
\hline Brazil & $\begin{array}{l}\text { A national study and several state level studies are being carried out in Brazil. A TEEB for Business } \\
\text { initiative is also underway aimed at engaging the Brazilian business community in the sustainable use of } \\
\text { biodiversity (TEEB 2011). }\end{array}$ \\
\hline India & $\begin{array}{l}\text { In } 2011 \text { India launched a national-level TEEB project to recognise, demonstrate and capture the value of } \\
\text { ecosystem services in India, and targets policy actions at both national and state levels. Within this } \\
\text { project, wetlands, forests and marine ecosystems have been identified as priorities. }\end{array}$ \\
\hline Portugal & $\begin{array}{l}\text { Building on the Portugal Millennium Ecosystem Assessment which was completed in 2009, a TEEB } \\
\text { assessment is now underway. }\end{array}$ \\
\hline France & $\begin{array}{l}\text { The French National Assessment of Ecosystems and Ecosystem Services, which was launched in } 2012 \\
\text { and is planned to be completed in } 2016 \text {. }\end{array}$ \\
\hline
\end{tabular}


Figure 5. The full set of ecosystem process, services, goods/benefits and values used in the UK NEA

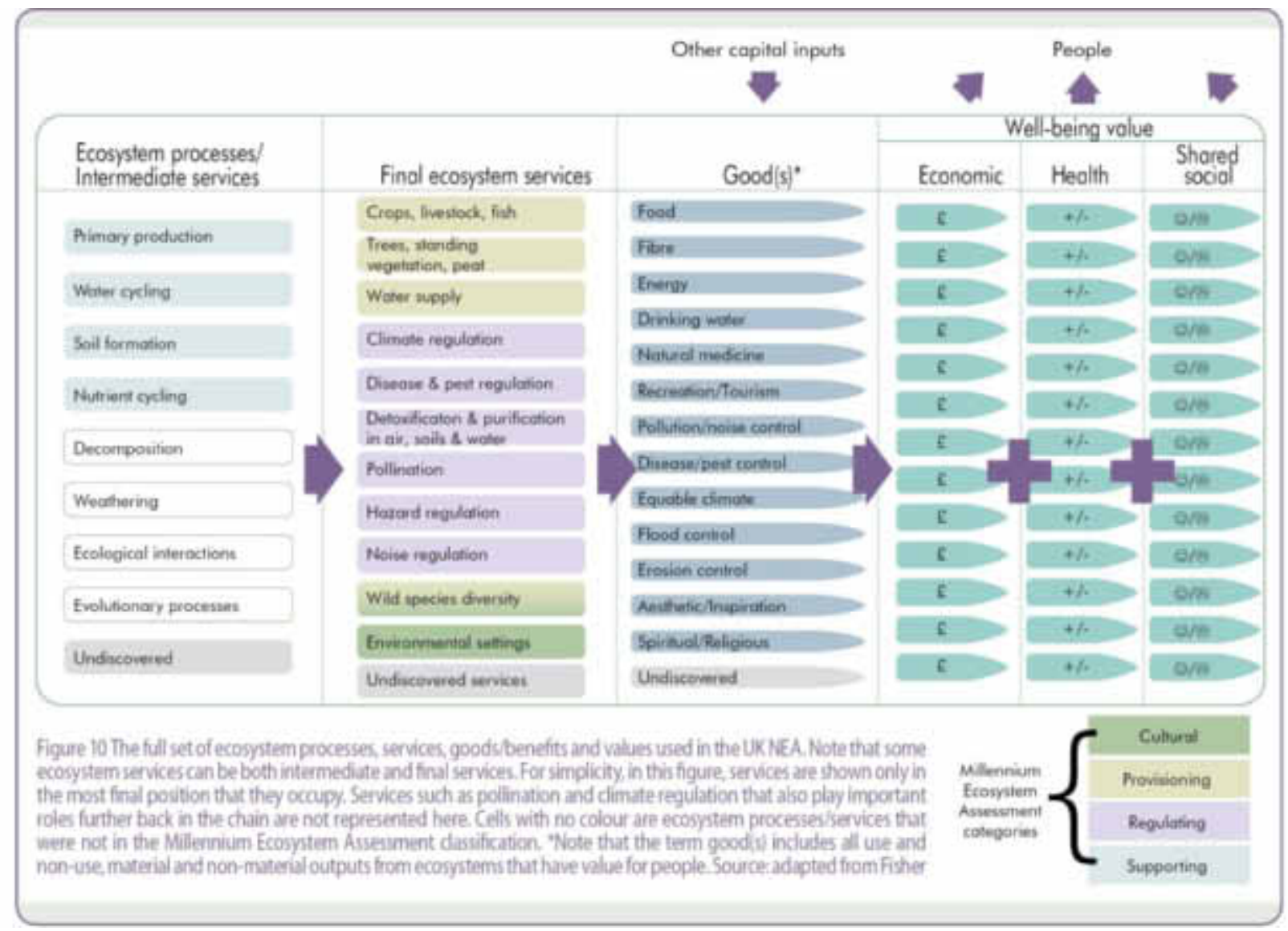

Source: UK NEA 2011.

The conceptual framework of the JSSA (Figure 6) is also based on the MA conceptual framework. This is due to three reasons: i) the centrality of human well-being in consideration of ecosystem services; ii) the acknowledgement of the interdependency, synergy, and trade-offs between ecosystem services and human well-being; and iii) the recognition that interdependency is impacted at different temporal and spatial scales. The JSSA, a study of the interaction between humans and terrestrial-aquatic landscapes (satoyama) and marine-coastal ecosystems (satoumi), utilises the concept of inter linkages in analysing the interdependency of ecosystems and humans (see Figure 7). Specifically the study explores three relationships: i) between ecosystem services in satoyama and satoumi, ii) between ecosystem services and human well-being, and iii) between space and time in satoyama and satoumi landscapes. 
Figure 6. Conceptual framework of the Japan Satoyama Satoumi Assessment (JSSA)

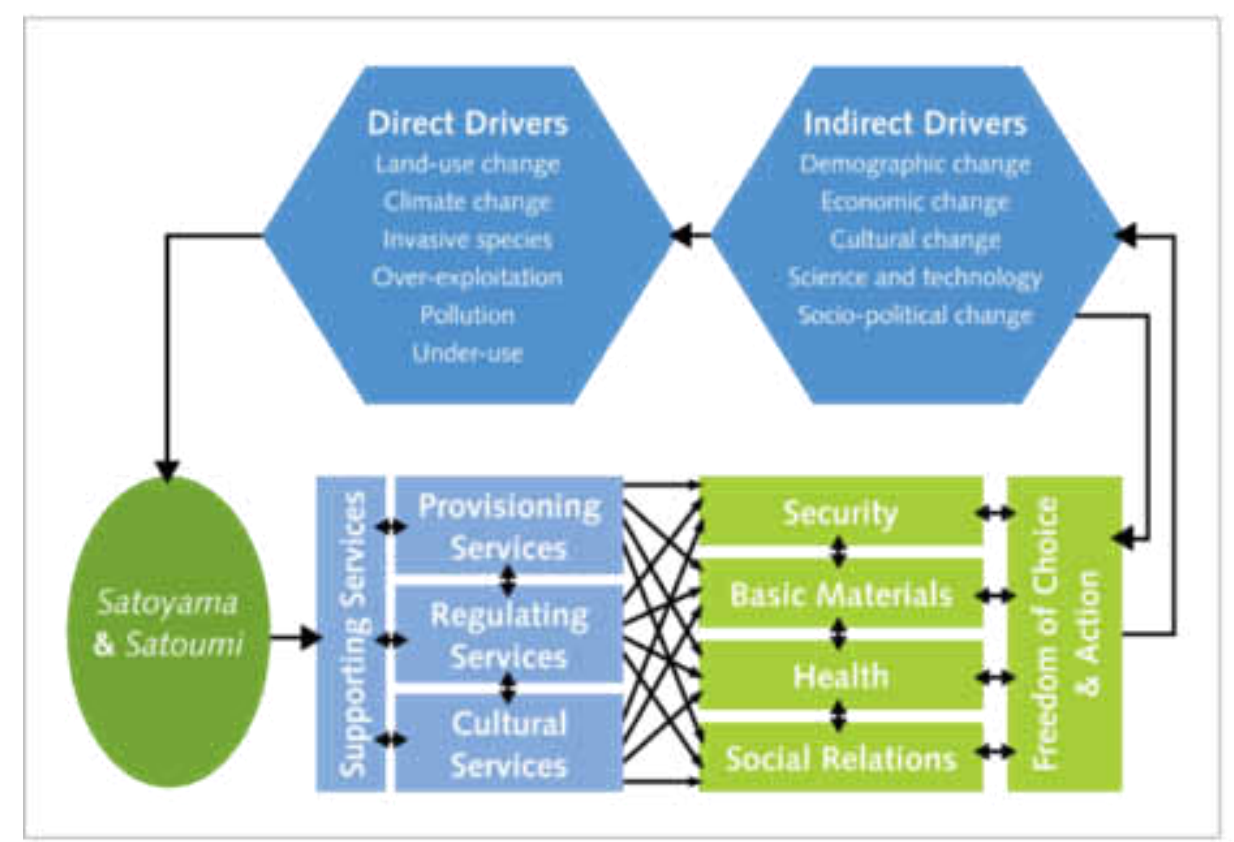

Source: JSSA 2010.

Figure 7. Inter linkage analysis for JSSA

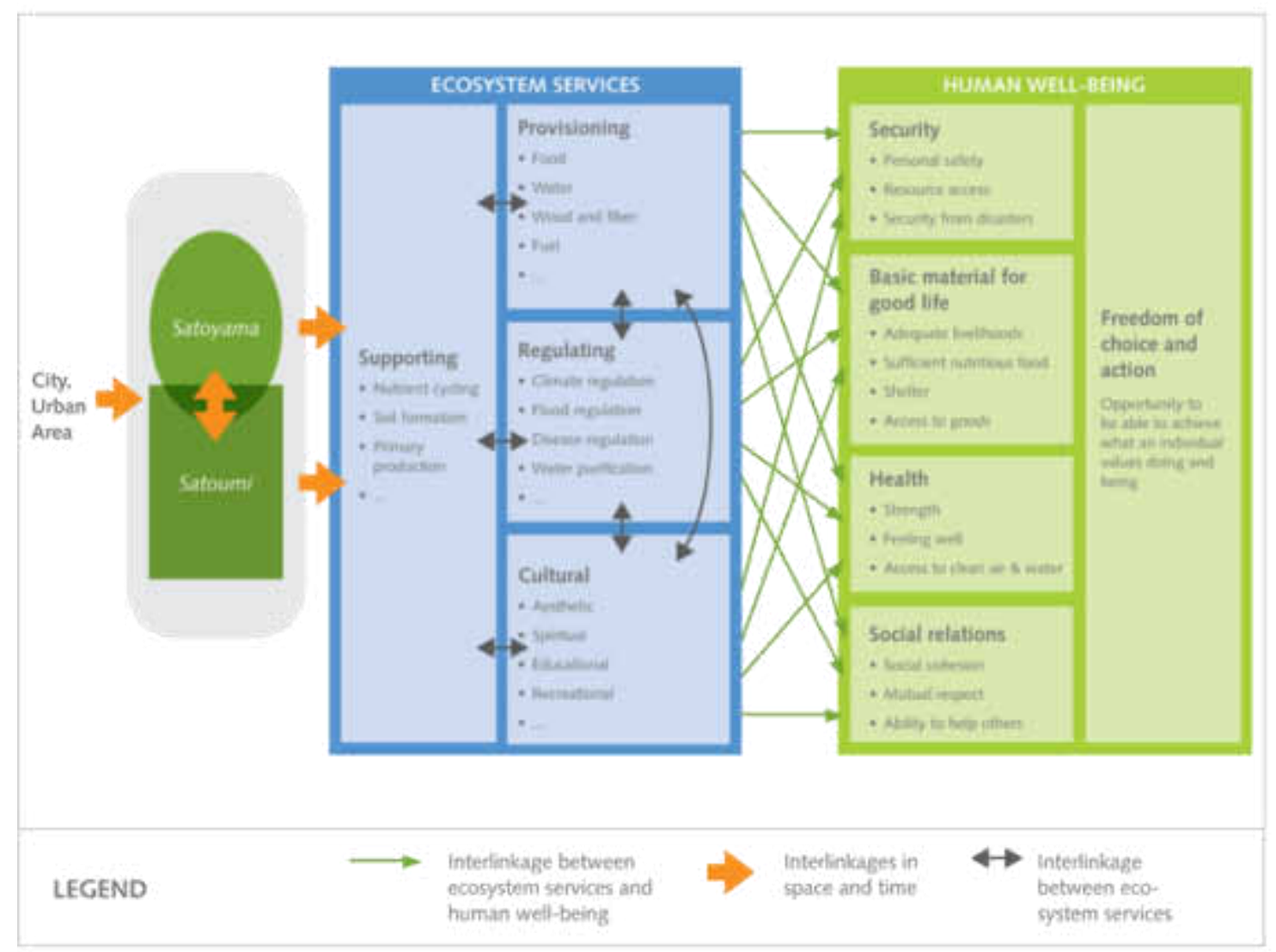

Source: JSSA 2010. 
The conceptual framework itself can be a powerful communication tool. The UK NEA's conceptual framework for example, has appeared widely in presentations to academics, to stakeholders from numerous sectors, and to practitioners. However, it has also been used within Defra to illustrate the link between Defra and different government departments including the Treasury and the Department of Health.

\subsubsection{Planning a Communication Strategy}

Guided by clear communication goals a Communication Strategy identifies the type of information that should be communicated to which target audiences using which channels. For example, a one-page set of key messages from the assessment will be more appropriate for high-level policy makers than a 30minute technical presentation on the valuation methods used, which may be better received by an academic audience. It is useful to consider the types of illustrations or key diagrams the assessment may wish to produce relatively early on in the implementation stage as these can take some time to evolve into effective communication tools.

The strategy also sets out expectations for internal communication. For example, when and how communication occurs both between and within the groups that make up the governance structure.

\subsubsection{Estimating necessary funding}

The cost of conducting an ecosystem assessment will vary considerably and therefore it is impossible to give definitive guidance on the budget required. Budgets will however be influenced by an assessment's spatial scale, the extent and nature of technical effort as well as the approach to participatory, communication and outreach processes (Ash et al. 2010) (see Box 2).

\section{Box 2. Elements that required resources for the UK NEA}

Different elements of the UK NEA that required funding are listed in descending order of magnitude

- Staff (Secretariat)

- Author costs (including a scientific writer)

- Valuation and human well-being analyses e.g. cost of primary research

- Meetings of funders, expert panel and user group

- Communications e.g. printing and design of interim and final reports

- Stakeholder engagement meetings

- Website development and maintenance

- Data costs e.g. licences 


\subsubsection{Implementation stage}

Discussion of the considerations that relate to the individual components of an ecosystem assessment process (status and trends, scenarios, response options, valuation) is outside the scope of this paper. However, further information can be found in Ash et al. (2010).

Peer review of the findings is a crucial stage of the assessment process. Development of the peer review process should be tailored to each assessment, reflecting its scale and context. Peer review by technical experts allows validation of the findings, thereby providing credibility. In addition, this stage encourages involvement of the user community, as users are given an opportunity before the end of the process to give feedback on the utility of the assessment's outputs. Therefore enough time should be allowed in an assessment's schedule for individuals to provide comments, for authors to address these comments and for the designated governance group to check that comments have been handled adequately.

Capacity building (e.g. learning by doing) is an integral part of the ecosystem assessment process; it will occur at all stages of the process and beyond the life time of an assessment. Capacity building is about the long term strengthening of human resources, institutions and organisational structures to be able to undertake ecosystem assessments which are relevant to decision makers. Further, it is about building capacity for decision makers to act on the assessment findings. Development of networks of experts either at local scales or international scales (such as the Sub-Global Assessment Network ${ }^{7}$ ) can build the capacity of coordinators of emerging NEAs to carry out assessments through the sharing of experiences and lessons learned.

\subsection{Achieving policy impact}

Three attributes: relevance, credibility, and legitimacy, increase the likelihood that the knowledge contained in an assessment will have influence (IPBES/1/INF/8). In addition, Ash et al. (2010) notes that an assessment will have greatest impact where consideration is given to both process and products, where stakeholders are fully engaged, and where assessment design follows scoping of user needs.

IPBES/1/INF/8 identifies that the policy impact of assessments, while it can in some cases be significant, is not usually assessed in a systematic or critical manner. Section 5 discusses the policy impact of completed assessments in more detail.

\subsubsection{Relevance}

Relevance refers to the ability of an assessment and its findings to address the particular concerns of a user. For example, an assessment could be considered relevant if the user is aware of it and if it informs his/her policy, behavioural or other decisions (UNEP/GC.25/INF/12). Policy relevance can improve if there is dialogue and interaction between decision-makers and expert assessors throughout the assessment process (UNEP and IOC-UNESCO 2009).

The level of detail of the assessment (a general overview or an in-depth investigation) should be planned in advance. The UK NEA was a multi-scale assessment as it analysed information at the UK and country level in order to inform decision-making at more than one scale. Therefore, key target audiences (policy-makers, managers and sectoral users, public) were identified from different scales in the planning stages. Consultation and communication with these audiences occurred throughout the process so that the end products were meaningful for each audience.

\footnotetext{
${ }^{7}$ http://www.ecosystemassessments.net/
} 
The Synthesis of the Key Findings for the UK NEA (UK NEA 2011) was relevant because its analysis and findings were closely related to the needs of identified decision-making processes.

\subsubsection{Legitimacy}

Legitimacy refers to the degree of political acceptability or perceived fairness of an assessment (UNEP/GC.25/INF/12).

Opportunity for a range of stakeholders to interact with experts throughout the process can help boost legitimacy, as it lifts the lid a little on the "black box" that an assessment might otherwise become. In addition, evaluation of assessment processes have concluded that when input is sought from those with a stake in the outcome, or when experts in these groups are directly engaged in assessments they are more likely to reflect assessment findings in their decisions and in their work (IPBES/1/INF/8). It is worth noting that these interdisciplinary networks, built in the process of ensuring legitimacy, can be an important and long lasting legacy of undertaking assessments.

A transparent process will also enhance the legitimacy of an assessment. For example, during the peer-review process the UK NEA Coordinating Lead Authors were asked to record how they had addressed comments by the reviewers, which included the principle stakeholders and other experts. The approach resulted in evidence that an individual's or organisation's input had been considered.

A clear mechanism to enable participants to air their concerns throughout the process is important as is a relatively equal balance of experts representing the various disciplines (natural scientists, social scientists, economists).

\subsubsection{Credibility}

Credibility refers to the perceived scientific and technical soundness of an assessment (UNEP/GC.25/INF/12). This attribute relates to the quality of the data, analytical methods and models used, and whether issues of particular significance from a scientific perspective have been included. Setting standards of inclusion of data and clearly identifying sources of data can help ensure credibility as regards the data used.

Transparency over the procedure for selecting experts can enhance credibility as can quality assurance and peer review. In the UK NEA uncertainty statements were assigned for key findings based on the level of evidence available and the degree of expert opinion that had been used. In addition, the technical chapters underwent two rounds of peer review and were individually 'signed-off' by the Expert Panel. In terms of the data used, this was largely robust, peer-reviewed datasets. The United Nations Environment Programme World Conservation Monitoring Centre (UNEP-WCMC), whose role was as Secretariat of the UK NEA process, was selected due to their independence from Defra in addition to their experience with ecosystem assessments.

The Spanish NEA established independent technical teams to lead the individual components of their assessment which ranged from the biophysical foundation for the study of ecosystems, to the impact on human well-being, to future scenarios. A core group of scientists integrated the results of the assessment into a synthesis report which was then peer reviewed by an international scientific advisory committee to ensure robustness of the results. Datasets used in the Spanish NEA were complimented by information gleaned from interviews, questionnaires and workshops.

The Science Assessment Panel of the JSSA provided leadership of the assessment process, which included determining the criteria and process for selecting authors, and overseeing information generated from the working groups. Any decisions made were first discussed and endorsed by the Board and, where 
necessary, the Governmental Advisory Committee. Similar to the UK NEA technical report, the national technical report of the JSSA underwent two rounds of reviews, overseen by an independent Review Panel, to enhance credibility.

Building capacity of the assessment process and lessons learned can play an important role in strengthening quality and credibility over time. Since its publication in 2011, the UK NEA has received international recognition of its approach used and steps forward made in the understanding of the links between ecosystem services and human well-being. The UK NEA has been discussed with South East Asian, Australian, US, Swedish, French, Israeli, and Chinese governments. In addition, fora such as the Sub-Global Assessment Network have been valuable in highlighting 'model' assessments, sharing lessons learned and building capacity in ecosystem assessments in general (see Section 6).

TEEB national studies could play a relevant role catalysing related action to maintain, restore and develop a country's ecosystem services and in promoting their integration into accounting and reporting systems at national and sub-national levels. In addition, these studies provide additional information that, if communicated to the public in an appropriate manner, could help to raise awareness for the value of ecosystems as 'natural capital' and support the acceptance of related conservation measures and their associated investment costs (TEEB 2011). Examples of initiatives underway are summarised in Box 1. 
ENV/WKP(2014)9

\section{POLICY IMPACTS OF NATIONAL ECOSYSTEM ASSESSMENTS}

By definition an ecosystem assessment is carried out at the interface between science and policy (or between "knowledge" and "action") and therefore a primary role of an assessment is to inform policy decisions (UNEP/GC.25/INF/12). Section 2 highlighted the need for assessments to be policy relevant, for example by synthesising information on current policy relevant issues and processes, thereby taking into account the needs of policy-makers. Section 3.2 described key attributes - relevance, credibility and legitimacy - that influence the impact the knowledge contained in an assessment can have.

It is useful to consider the range of spatial scales that ecosystem assessments can have an impact on (i.e. national, and regional, and international). The policy impact of global assessments is not often assessed and if it is, the process can be difficult, and the true policy impact not known for many years following the completion of the assessment. In this regard impact is more often assessed and understood for those assessments that are periodically repeated as this has been an essential step in securing the funds and in some cases the mandate for repeating the exercise (IPBES/1/INF/8). Coordinators of future assessments should be encouraged to determine early in the process how policy impact will be accessed. For this reason 'Policy Impacts' appears as a category in the Intergovernmental science-policy Platform on Biodiversity and Ecosystem Services (IPBES) Catalogue of Assessments ${ }^{89}$, in an attempt to capture valuable information on the success of different assessments in impacting policy making. This section considers the evidence of policy impacts at different spatial scales.

\subsection{Impact of National Ecosystem Assessments at the national level}

Evidence of policy impacts at the national scale are discussed below in relation to the UK NEA, the Spanish NEA and the Portuguese NEA.

\subsubsection{UK National Ecosystem Assessment}

The policy impact of the UK NEA was immediately seen upon release of its key findings. This was partly due to timing as the Government's Natural Environment White Paper (NEWP 2012) The Natural Choice: securing the value of nature was being developed during the final stages of the UK NEA. The UK NEA contributed to the evidence base in the NEWP which was used to formulate priority actions for the Government to take to ensure the sustainable management of the country's environment (see examples discussed below).

The UK NEA underlines the importance of having the correct authorising environment and engaging closely with the key stakeholders (IPBES/1/INF/8). Aligning the assessment delivery to coincide with key

\footnotetext{
${ }^{8}$ The second session of the plenary meeting on IPBES (Panama, 16-21 April 2012) called for the development of an online Catalogue of Assessments. The primary intention is to provide information from existing and ongoing assessment processes and lessons learnt and to provide direct access to assessment reports and guidelines as a resource for practitioners.

${ }^{9}$ http://catalogue.ipbes.net/
} 
opportunities when policy may change, such as the release of documents by Governments setting out details of future policy, rather than producing something policy relevant when there is no immediate plans for policy to be revised can also strengthen the impact of the assessment.

The NEWP (2011) set out a number of commitments which included supporting a further phase of the UK NEA (see Box 3). For example:

- The UK NEA illustrated how financial benefits obtained from nature (natural capital) are often underestimated or overlooked. Therefore one of the commitments in the NEWP is to establish an independent Natural Capital Committee to advise the Government on the state of English natural capital.

- In response to the UK NEA highlighting the country's dependence on ecosystems abroad to supply goods and services to the economy, the NEWP committed to supporting a new international coalition of business, coordinated by the TEEB for Business Coalition to help business to understand and address their environmental impacts.

- The UK NEA showed the changing (in some cases declining) status of habitats and the services they provide and identified the need for a more coherent approach to environmental action in order to protect and improve the natural environment. The NEWP committed to establish new Nature Improvement Areas (NIAs) based on local assessments of opportunities for restoring and connecting nature on a significant scale, and including them in local planning strategies. 


\section{Box 3. The UK NEA follow-on phase}

In 2011 the UK NEA delivered a wealth of information on the state, value (economic and social) and possible future of terrestrial, freshwater and marine ecosystems across the UK, but also identified a number of key uncertainties. In the White Paper on the Natural Environment (NEWP 2011), the Government committed to adding to this knowledge base and is therefore funding a two-year Follow-On phase of the UK NEA. The Follow-On phase is further supported by the Welsh Government and three UK research councils. The overarching aim of the Follow-On phase is to further develop and communicate the evidence base of the UK NEA and make it relevant to decision and policy making at different spatial scales across the UK and to a wide range of stakeholders.

A significant component of the Follow-On phase is primary research. Grouped into four themes the research is focusing on economic analysis; cultural ecosystem services and cultural, shared, and plural values; future ecosystem change; and tools and supporting materials. The following Table lists the specific research aims.

Research aims of the UK NEA follow-on phase

\begin{tabular}{|c|c|}
\hline \multirow[t]{3}{*}{ Economic analysis } & To develop the framework and address evidence issues in order to perform a Natural Capital Asset Check \\
\hline & $\begin{array}{l}\text { To provide a scoping review and research agenda for understanding the macro-economic implications of } \\
\text { ecosystem service change and management in the UK }\end{array}$ \\
\hline & $\begin{array}{l}\text { To conduct economic analysis of the value of ecosystem service change to the UK, examining the trade- } \\
\text { offs between selected ecosystem services and their values arising from alternative land-uses }\end{array}$ \\
\hline & To value ecosystem services in coastal and marine environments \\
\hline \multirow{2}{*}{$\begin{array}{l}\text { Cultural ecosystem } \\
\text { services and cultural, } \\
\text { shared and plural } \\
\text { values }\end{array}$} & To extend the theoretical, methodological and practical understanding of Cultural Ecosystem Services \\
\hline & $\begin{array}{l}\text { To understand the respective impact of cultural, shared and plural values versus aggregated individual } \\
\text { values on decision-making and outcomes }\end{array}$ \\
\hline \multirow[t]{3}{*}{$\begin{array}{l}\text { Future ecosystem } \\
\text { change }\end{array}$} & $\begin{array}{l}\text { To deepen the analysis of the six scenarios developed in the UK NEA to facilitate the inclusion of a wider } \\
\text { range of ecosystem services and explore how these influence well-being values }\end{array}$ \\
\hline & $\begin{array}{l}\text { To assess the viability and interaction of current policies/practices/ institutions for delivering an ecosystem } \\
\text { approach against the UK NEA scenarios, and therefore, the implications for the design of future response options }\end{array}$ \\
\hline & $\begin{array}{l}\text { To examine the cultural and behavioural barriers and enablers to embedding consideration of ecosystem } \\
\text { knowledge in policy decision-making }\end{array}$ \\
\hline $\begin{array}{l}\text { Tools and supporting } \\
\text { materials }\end{array}$ & $\begin{array}{l}\text { To review, develop and enhance tools and resources to take account of the findings/methods of the UK } \\
\text { NEA }\end{array}$ \\
\hline
\end{tabular}

\subsubsection{Spanish National Ecosystem Assessment}

The Spanish National Ecosystem Assessment began in Spain in 2009, completed its first phase (the biophysical dimension) in 2012 and launched a second phase (the socioeconomic dimension) to be completed in 2014. It is the first analysis done on the status and trends of the services of terrestrial and aquatic ecosystems of Spain and its contribution to the well-being of its inhabitants (EME 2011). This project represents a significant change in perspective in the field of conservation in Spain since, without abandoning the intrinsic values of nature, it promotes instrumental values (extrinsic values) linking ecosystem conservation with the different dimensions of human welfare.

The results of the Spanish NEA are expected to help to break down barriers and build bridges between scientific knowledge and decision making by using interdisciplinary, empirical data to visualise the complex relationships that exist between conservation of ecosystems and human welfare of generations present and future. It is also expected to serve to increase awareness of Spanish society, including the business sector on the importance of ecosystems and biodiversity in the different components of human well-being, including economic development (EME 2011). 
To date, the Spanish NEA has been cited in the Spanish Strategic Plan for Biodiversity and Natural Heritage (2011-2017) and will contribute to a number of actions relating to indicators of change in ecosystems, economic valuation studies, mapping ecosystem services, improving mechanisms for communicating with society and improving knowledge and understanding for more informed policy making. In addition, the Spanish NEA is part of the EC MAES described in Section 5.2.1. The next step is to conduct a detailed socio-economic valuation taking into account the use and non-use values of biodiversity, the results of which are anticipated to have further policy influence on policy decisions and direction.

\subsubsection{Portugal Millennium Ecosystem Assessment}

Although there was no formal mandate, several stakeholders participated actively in the design of the National Ecosystem Assessment of Portugal (PtMA), which provides a critical assessment of the current state of knowledge concerning the consequences of ecosystem changes for human well-being in the country.

The production of the PtMA catalyzed the incorporation of the concept of ecosystem services and assessment findings in several legal documents related to nature management and conservation: Legal Regime of Nature and Biodiversity Conservation; National Strategy for the Forest; Management Plans of protected areas; Strategic Environmental Assessments; Environmental Strategic Evaluation of the Program for Rural Development; and Agro-environmental policies follow-up (IPBES Catalogue of Assessments 2012a).

The concepts of ecosystem services and ecosystem services valuation and assessment findings were also introduced and used in several fields: Secondary school programs; University courses; and the Private sector (CONFAGRI) through documents, website and agro-environmental policies follow-up (IPBES Catalogue of Assessments 2012a). In addition, assessment team members were invited to participate in policy assessment and development in the fields of environment and education.

\subsection{Impact of National Ecosystem Assessments at the regional level}

Policy impacts at the regional level are discussed in the context of the EU Working Group on Mapping and Assessment of Ecosystems and their services (MAES).

\subsubsection{EU Working Group on Mapping and Assessment of Ecosystems and their Services}

Developing an assessment with careful consideration of the wider policy context in which the findings can be used to inform a number of priorities, increases the likelihood that the assessment has a more significant policy impact (IPBES/1/INF/8). An example of this is the development of Target $2^{10}$ of the EU Biodiversity Strategy to $2020^{11}$, which provides a policy context for an Ecosystem Assessment for Europe, building on on-going activities at national, European and global levels, in particular the UK NEA and the Convention for Biological Diversity Strategic Plan for Biodiversity 2011-2020 and the Aichi Biodiversity Targets $^{12}$ (responding to targets 2, 14 and 15) (IPBES/1/INF/8).

\footnotetext{
10 "By 2020, ecosystems and their services are maintained and enhanced by establishing green infrastructure and restoring at least $15 \%$ of degraded ecosystems" (European Commission, 2011).

${ }^{11}$ http://ec.europa.eu/environment/nature/biodiversity/comm2006/pdf/2020/1_EN_ACT_part1_v7\%5b1\%5d.pdf.

${ }^{12}$ http://www.cbd.int/sp/targets/
} 
To reach Target 2, different actions have been set up, one of which is Action 5: "Improve knowledge of ecosystems and their services in the EU". Within this framework, each EU Member State is required to contribute to the achievement of Target 2 by:

- Mapping and assessing the state of ecosystems and their services in its national territory (by 2014).

- Assessing the economic value of such services and promoting the integration of these values into accounting and reporting systems at EU and national levels (by 2020).

To support EU Member States (MS) in operationalising Action 5, and ensure consistency in mapping and assessment approaches across MS, the European Commission has created a working group on Mapping and Assessment of Ecosystems and their Services (MAES).

The work builds on the outcomes of the MA and TEEB studies. It also capitalises on the experience and newly developed knowledge from on-going assessments, in particular the national TEEB studies currently undertaken by EU and its MS. The European Ecosystem Assessment will benefit from the outcomes of the reporting obligations of the MS under EU environmental legislation on the status of biotic components of ecosystems and abiotic environmental conditions (EC 2012).

The mapping and assessment work under MAES (see EC, 2013; 2014) builds on the knowledge base for ecosystems and their services in Europe, creating an essential baseline for supporting decision-making on Green Infrastructure (Action 6 of the EU Biodiversity Strategy) so that ecosystem status improves and the delivery of multiple ecosystem services is sustainably ensured in the long-term. Furthermore, spatial information on the delivery of and the demand for ecosystem services will provide baseline data to measure net future gains or losses (Action 7 of the EU Biodiversity Strategy) and will support the development of financial instruments to fund investments in nature (EC 2012). It also intends to play a key role in identifying regions in which measures are likely to result in cost-effective progress towards both new biodiversity conservation and ecosystem services targets adopted by the EU Biodiversity Strategy to 2020 .

In addition, there is clearly a strong link between Action 5, the work of MAES, the work on natural capital accounts and the Green Economy. The mapping and assessment work aims to contribute to the internalisation of ecosystem service safeguarding into the design and implementation of different policies in many areas, such as nature and biodiversity, territorial cohesion, agriculture, but also other domains such as transport and energy, helping to achieve the Europe 2020 target, particularly the resource efficiency goal.

\subsection{Impact of National Ecosystem Assessments at the international level}

Policy impact at the international landscape is discussed in relation to the newly established Intergovernmental science-policy Platform on Biodiversity and Ecosystem Services (IPBES) ${ }^{13}$.

\subsubsection{The Intergovernmental science-policy Platform on Biodiversity and Ecosystem Services}

The Intergovernmental science-policy Platform on Biodiversity and Ecosystem Services (IPBES) is being established to respond to the need for scientific information related to biodiversity and ecosystem services from Governments, relevant Multilateral Environmental Agreements (MEAs), United Nations bodies, as well as other relevant stakeholders.

\footnotetext{
${ }^{13}$ http://www.ipbes.net/
} 
Although the full work programme of the platform is still under development, assessments are to feature as one of the four functions of IPBES: to perform regular and timely assessments of knowledge on biodiversity and ecosystem services and their inter linkages. It is possible to envisage that the platform's Programme of Work will have a focus on assessments, with its three other functions (knowledge generation, capacity-building, and policy-relevant tools and methodologies) integrated into the assessment process (UNEP/IPBES.MI/2/2).

While recognizing that IPBES will not itself be carrying out national assessments, it is anticipated to become a key platform to promote and catalyse sub-global assessments, ensure full use of national, subregional and regional assessments and knowledge, and to some extent facilitate them through adopting or promoting support tools.

National assessments are particularly relevant due to the role that they play in national and subregional policy formulation and decision making. Their promotion and facilitation by IPBES will contribute to strengthening the science-policy interface on biodiversity and ecosystem services, and to integrate ecosystem values into national and local accounting.

In addition, national assessments can also play a key role in contributing to a bottom-up approach to global and regional assessments. It is anticipated that the platform's regional and global assessments would draw heavily on findings from national, local and sub-regional assessments, including those undertaken within the Sub-Global Assessment Network and other initiatives (UNEP/IPBES.MI/2/2). 
ENV/WKP(2014)9

\section{LESSONS LEARNED FROM NATIONAL ECOSYSTEM ASSESSMENTS}

A review of lessons learned during the assessment process can serve as a valuable tool to inform future practitioners and enhance the overall efficiency and success of subsequent assessments. The scope of this paper is to compile lessons from assessments conducted at the national scale, although it should be noted that valuable lessons on the assessment process can also be drawn from those conducted at the global and regional scales as well as thematic assessments. The respective teams responsible for the national ecosystem assessments of the UK, Portugal, Spain and Japan have examined their own experiences with regards to developing and implementing an ecosystem assessment. These lessons are summarised below. It is evident that, despite regional variations in scope and objectives, many of these lessons are similar between the different assessments.

\subsection{UK National Ecosystem Assessment}

At the conclusion of the first phase of the UK NEA, the team reflected on their experience of the ecosystem assessment process as a whole, and produced advisory notes to inform future phases of work. Lessons learned were drawn from aspects of the assessment which went particularly well, areas in which efficiency may have been improved, and unforeseen opportunities that presented themselves during the process that enhanced the UK NEA outputs. When reviewing the lessons learned during the development and execution of the UK NEA, six distinct categories were created into which these lessons could be grouped:

1. Policy Impact

2. Data and Advice

3. Governance

4. Team Familiarisation

5. Stakeholder Engagement

6. Management and Communication

\subsubsection{Lesson 1: Policy Impact}

An important lesson from the UK NEA was that opportunities to influence policy should be identified early and a strategy devised as to how to ensure assessment outputs have as much influence or impact as possible.

The release of the UK NEA, which was timed to coincide with the production of the Government's Natural Environment White Paper (NEWP 2011), allowed for the immediate uptake of the evidence base underpinning the UK NEA. This also enabled the work of the UK NEA to be exposed to policy makers directly, thereby creating the opportunity to influence policy. 
1. These kinds of opportunities may be difficult to anticipate, however there is significant value in considering whether the release of assessment results are in line with potential upcoming policy reviews.

\subsubsection{Lesson 2: Data and Advice}

A second important lesson learnt from the UK NEA was the need to ensure that relevant data can be accessed in order to build a robust and scientifically valid evidence base, together with the realisation that advice from experts will also be required.

It was understood from the outset that the UK NEA would be 'data hungry'. Therefore considerable effort was invested to ensure the variety of data required could be accessed. This involved contacting data holders as early as possible and negotiating data use. A considerable, but not insurmountable challenge to overcome was the different methodologies and data formats used across the constituent countries of the UK, which impacted on data analysis.

In regards to seeking expert advice, the participation of a range of specialists from different institutions in the UK NEA was encouraged. Lead authors also actively sought a wide academic input to chapters, which was in line with the Secretariat's aim to be as inclusive as possible throughout the process.

The utilisation of strong leadership skills within the team, along with an effective cascade system, was required to drive delivery of outputs from a relatively large group of contributors. The support and advice of scientists with previous experience of assessments also proved to be useful in this regard.

\subsubsection{Lesson 3: Governance Structure}

Establishing a strong governance structure early on is advised, as this allows groups to plan their time and resources according to project expectations, enhancing the smooth running of an assessment.

From the outset, five main groups were established in a formal governance structure for the UK NEA: Co-Chairs, Expert Panel, Client Group, Co-ordinating Lead Authors and User Group.

Co-Chairs are designated to represent the UK NEA publicly, take decisions on content and drive the assessment forward. An Expert Panel of 27 leading academics from disciplines spanning the assessment acted to coordinate academic input, peer review and synthesise findings. The Client Group of six funding bodies controlled resource allocation and provided access to policy and government data together with relevant expertise. The Co-ordinating Lead Authors were responsible for gathering, reviewing, and analysing data and information required to produce their respective chapter. Finally, a User Group of interested parties from government agencies, the public, private and voluntary sectors was established to advise from the perspective of users of the assessment outputs.

\subsubsection{Lesson 4: Team Familiarisation}

As experts from many different disciplines (e.g. social science and natural science) are expected to work together for a period of time during the ecosystem assessment process, a short introductory workshop or meeting is advised as a preliminary step. This will allow them to discover each other's needs and expectations and to discuss any differing terminology or language definitions.

The experts will also need to adapt to each other's potentially diverse working practices across disciplines and institutions. The provision of time to enable these specialists to get together in an informal setting prior to the commencement of official operations can prevent interruptions to the work plan further down the line. 


\subsubsection{Lesson 5: Stakeholder Engagement}

Identifying and involving a range of potential user groups at several stages of the ecosystem assessment process helps to enhance the shape, content and uptake of the assessment. A valuable lessons learnt from the UK NEA is that stakeholders should be engaged early and consulted often.

For the UK NEA, stakeholders were invited to express an interest in the assessment before it was commissioned to suggest experts and locate potentially useful data sources. A User Group of selected stakeholders was established and used for a variety of functions - e.g. as a sounding board (e.g. for the scenarios), for data access, for peer review and for communication throughout the assessment. Direct briefing of the key stakeholders just prior to publication resulted in very positive public statements on the report. Ministers (and their officials) across government (e.g. Finance Minister) were recognised as particularly important stakeholders and were therefore engaged directly prior to launch to gain support for the Assessment.

\subsubsection{Lesson 6: Management and Communication}

The management of the UK NEA was found to be increasingly challenging as ambition intensified along with the diverse User and Client needs. Having an independent, non-academic, but technically competent Secretariat assisted in the management of the assessment, and having strong, energetic Co-Chairs was essential. Communication between groups was also important, especially in the later stages of the assessment, to make sure messages were shared, although there was still a need for individual meetings. It is useful to define early on who has the ultimate decision making authority on particular matters as this prevents multiple lines of communication opening up when there are disagreements.

\subsection{Lessons from the Portugal Millennium Ecosystem Assessment}

Henrique Miguel Pereira (University of Lisbon) identified five distinct lessons, drawn from the experiences of the various Portuguese NEA facilitators (IPBES Catalogue of Assessments 2012a):

1. Early and continued engagement of users.

2. Use mostly scientific knowledge already available and only do research to fill gaps.

3. Combine qualitative and quantitative, biophysical and economical valuation, based on data available and existing expertise.

4. Multi-scale assessments need more time and resources.

5. Invest in communication with the public.

The first and last lessons, regarding user engagement and communication with the public, can be directly linked to UK NEA Lesson 5 ('Stakeholder Engagement'). Both the UK and Portuguese NEA extol the virtues of sustained commitment to identifying and involving a range of potential user groups at several stages of the ecosystem assessment process. Time invested in seeking advice from several sources may seem to be a protracted approach, but it is one which pays dividends when, upon completion, these 'advisors' provide their support, both privately and publically.

The use of current knowledge and existing expertise within an ecosystem assessment is also noted as key by the Portuguese (Lesson 2 and 3) and UK (Lesson 2) NEAs. Locating and accessing the large amount of data required over a relatively short time scale is an important phase in the ecosystem assessment, not only to ensure the robustness of results but also to avoid the escalation of project costs with regards to data provision. 
The Portuguese NEA emphasises the point that 'multi-scale assessments need more time and resources'. Similarly the UK NEA advises that, in order to accommodate any potential challenges that may arise as the project progresses, the placement of a secure governance structure is essential. These solid foundations allow the NEA to expand and develop organically, without wasting substantial time and resources on issues such as questions of overall authority in times of disagreement.

\subsection{Lessons from the Spanish National Ecosystem Assessment}

The Spanish NEA identified a number of lessons:

\subsubsection{Lesson 1: Policy-science interface}

The Spanish NEA was initially conceptualised as a scientific project after the global Millennium Ecosystem Assessment (MA). However, during the process a strong policy need at both the national and international levels was identified, which the project could help to address. The project coordination group, composed of key policy and scientific stakeholders, developed the objectives of the Spanish NEA with a double aim: carrying out a robust, scientific and independent research exercise, while at the same time delivering results that could inform policy at different levels (i.e. global, EU and national agreements and obligations). The Spanish NEA attempted to use a common language between scientist and policy makers, and to establish a forum to discuss best ways to demonstrate the direct dependence of humans on biodiversity and ecosystems, working under a pluralistic and multidimensional framework.

\subsubsection{Lesson 2: Typology and classification of ecosystems and services}

There are many ways to classify ecosystem services (i.e. MA, TEEB and Common International Classification of Ecosystem Services (CICES)) therefore any new ecosystem assessment process should build on these existing ecosystem service classification systems. Similarly the proposed ecosystem classification should be compatible with classifications used at national and regional scales to ensure consistency and ease of comparability. Information from a more detailed classification at a local scale and at a higher spatial resolution should be compatible with these classifications and could be aggregated in a consistent manner.

\subsubsection{Lesson 3: Ecosystem service research should combine the three value-domains: biophysical, socio-cultural and economic}

The definition of the term human well-being used in the Spanish NEA follows the postulates from Ecological Economics and refers to the quality of life of an individual or society, which is understood as the capacity of the individual or society to meet their needs within the ecosystem's biophysical limits in order to enjoy a good life. The ecosystem's capacity to supply services determines the range of potential uses by society, having an influence on socio-cultural and monetary values. At the same time, sociocultural values have an influence on monetary values, because preferences, ethical and moral motivations determine the 'utility' that a person obtains from a particular service (Martin-Lopez et al. 2013). Those interdependencies and the different information provided helps to explain why ecosystem service research should combine the three value-domains (biophysical, socio-cultural, and economic) to properly inform the environmental decision-making process.

\subsubsection{Lesson 4: Need for a common framework to analyse the complex relationships established between ecosystems and human systems}

The Spanish NEA used the Driver-Pressure-State-Impact-Response (DPSIR) framework to analyse the complex relationships between ecosystems and human systems in Spain from a holistic point of view. The DPSIR framework is a common approach to explore the relationships between human-nature systems 
because it provides an organised structure to analyse the causes, consequences and responses to changes. The Spanish NEA adapted the DPSIR framework in order to analyse the connections between environmental change, ecosystem services, human well-being and the society's response to preserve the ecosystem service flow.

\subsubsection{Lesson 5: Multiscale analysis}

One of the main challenges for the Spanish NEA has been to integrate results from different scales that were obtained using the same conceptual framework, but using a series of methodologies which were not directly associated to the Spanish NEA. Five case studies of various scales but applying the same conceptual framework were included in the assessment: a) at national level (i.e. the Spanish NEA project), b) at regional level (i.e. a case study carried out at Biscay ${ }^{14}$ ), c) at ecosystem level, d) at watershed level (i.e. two case studies on the south-eastern semi-arid watersheds were included), and at local level (i.e. two natural parks were presented).

\subsubsection{Lesson 6: Mapping ecosystems and their services}

Analysing and mapping the spatial relationships of ecosystem services to the various components of the conceptual model (biodiversity, drivers of change, response options) can be useful for spatially explicit prioritisation including identifying synergies and trade-offs among different ecosystem services, and between ecosystem services and biodiversity. Maps can also be used as a communication tool to initiate discussions with stakeholders, visualising the locations where valuable ecosystem services are produced or used and explaining the relevance of ecosystem services to the public at the local level.

\subsubsection{Lesson 7: Communication, education and social participation}

An NEA should be designed as a communication tool to show the links between ecosystems, biodiversity and human well-being. Therefore, the conservation of ecosystems and biodiversity must be addressed not only by experts in ecosystem management, but also requires close collaboration between scientists, the public sector and the public through participatory processes. There is great potential for the participation and involvement of governmental and nongovernmental entities that share the same goals and strategies proposed by Spanish NEA. An NEA's results and approaches should be included in formal environmental education systems as a new way of viewing, thinking and acting in relation to our ecosystems and biodiversity.

\subsection{Lessons from the Japan Satoyama and Satoumi Assessment}

The facilitators of the JSSA acknowledged that this assessment was an experiment in applying the MA conceptual framework to different scales and as such the assessment has provided a rich learning experience for the stakeholders involved in the process. The iterative and bottom-up approach employed by the JSSA has enhanced capacity during the course of the assessment, in which a number of changes and modifications had to be made in accordance with the users' needs and the dynamic nature of satoyama and satoumi landscapes. Indeed, some tensions arose between the desire to follow top-down and prescribed guidelines and the mission to meet various users' needs and local/ regional specificities (Duraiappah et al. 2012). The Japanese assessment process therefore provided some practical lessons for future assessment work which include:

1. Identify a scale that is relevant to the users/stakeholders for better impact and use of the assessment findings for decision-making and policymaking.

\footnotetext{
${ }^{14}$ http://www.ehu.es.
} 
2. Define an assessment scale in accordance with the natural and climatic conditions of conducting the scientific assessment. Although JSSA adopted a clustering approach, which follows the socioeconomic component and the ecological and climate component, the scale in some of the clusters was not very relevant to either the social or ecological scale. Therefore the gap between the social and ecological scales needs to be considered when determining assessment scales.

3. Facilitate intimate and continuous communication among different stakeholders who have varying knowledge systems so as to create a valuable epistemic community of scholars and deepen the understanding of the basic concepts that are critical to move ahead with and complete the assessment work.

4. An adequate budget, as well as time and human resources, are essential for maintaining the momentum developed around an assessment initiative, to respond to unforeseen changes to the process and consequently to complete the assessment. For example, the JSSA adjusted their assessment process as a result of broad consultations with a wide range of stakeholders in Japan.

5. Engage users and stakeholders through an interactive process in which a variety of stakeholders from different backgrounds, disciplines and sectors communicate and exchange their views, can provide a useful network and sometimes bring in a new actor or activity during the course of an assessment. 
ENV/WKP(2014)9

\section{KEY ISSUES IN DEVELOPING PRACTICAL GUIDANCE FOR SUCCESSFUL ECOSYSTEM ASSESSMENTS}

The development of a concise guidance document, highlighting a stage by stage process by which to implement these lessons is a challenging task, as each ecosystem assessment is unique, with outputs inexorably linked to the scale and location in question. However, as discussed in Section 6, there are underlying themes that can be extracted from the lessons learned by each NEA, and these experiences, while not duplicated exactly, may have been shared by other ecosystem assessment teams. This section summarises key issues in developing practical guidance for successful ecosystem assessments. ${ }^{15}$

\subsection{Define clear, policy-relevant questions}

Clear research questions are vital. Questions should be defined in close consultation with key audiences and users, and should reflect the assessment's wider objectives. Key characteristics of research questions include that they should be:

1. Demand-driven - i.e. linking to national priorities and political windows of opportunity, particularly development goals; and

2. Policy-useful - i.e. relevant to a topical policy question and can be easily translated for use by decision-makers, as well as applicable to key sectors (e.g. industry, agriculture, national planning offices), as they will be the final users of the assessment.

For example, a local scale assessment in Thailand, supported by the UNDP-UNEP Poverty Environment Initiative (PEI), found that responding to the needs of local decision-makers and interest groups dramatically improves the likelihood that the assessment will be of interest and value, and in turn leads to improved uptake of results into management decisions.

\subsection{Carefully plan and set clear boundaries of scope and scale}

A realistic study design which takes into account the wider context of the assessment can provide direction to ensure assessment objectives are met. A comprehensive overview of the entire assessment process with mapping of how goals will be reached can provide practical guidance, accompanied with a conceptual framework to focus key issues and relationships. To direct specific tasks and activities, a governance structure including leadership and decision-making guidelines helps to define roles and responsibilities, while an overall analytical framework can help to direct data gathering.

15 This section has also been informed by discussions at the $3^{\text {rd }}$ annual meeting of the Sub-Global Assessment Network (SGA Network - http://www.ecosystemassessments.net/) in Bilbao (December 2011), where participants were asked to identify significant challenges they had faced in the field of ecosystem assessment, potential solutions to these challenges, and from these, derive the main lessons learned in terms of 'the most important things a practitioner should think about when beginning a new sub-global assessment' (SGA Network 2012b). 


\subsection{Be inclusive}

To provide a comprehensive appraisal of the environment which includes ecological, social and economic factors, a suitably skilled team must be assembled. This includes a range of technical experts as well as relevant stakeholders to provide grounded, practical guidance. Inclusivity secures buy-in, ownership and the production of useful outputs. Diverse groups also bring different understandings of concepts and language - developing a shared understanding from the outset will be necessary to overcome this.

\subsection{Apply a clear governance structure}

The assessment team will hold a great deal of collective knowledge; governance and leadership are critical for getting the most out of it. Assigning specific roles and responsibilities, based on proven skills and experience, can maintain engagement, co-ordination and progress against objectives. Clear tasks and achievable goals can also instil motivation and enable monitoring of progress. Communication channels are necessary to maintain a continuous dialogue within and between groups, ensuring coherence and providing opportunities for negotiation, collaboration and creativity. Regular meetings are a key feature, particularly for maintaining ownership. An overall balance between formalised guidance and flexibility is important, since individuals will also require room to learn at different rates. An on-going iterative process will be necessary to accommodate this, particularly in the initial stages.

\subsection{Promote the assessment concept}

All stakeholders should feel ownership of the assessment and see value in the process and products. This may require some 'selling' of the assessment concept to generate visibility and interest. External communications need to begin early and remain well directed towards key users. Successful 'marketing' requires articulation of an assessment's benefits, before the process begins, to a range of audiences and through a variety of media and fora. Using different languages and communication tools for different audiences can provide the necessary focus, with evidence of success and reference to specific examples. In particular, links to major national priorities can act as a selling point. If necessary, an initial pilot study can help to verify assessment concepts and stimulate interest for a more comprehensive assessment through 'learning by doing'. Emerging opportunities to secure buy-in should also be captured as the assessment proceeds. Trust and ownership can be created through sharing results and learning together. This requires effective communication, which can be guided by a communications plan detailing who, when and how to engage.

\subsection{Understand the decision-making context}

For results to be put into action, assessment outputs need to be relevant - i.e. based on an understanding of how they are going to be used, but this should also be balanced with flexibility. The assessment needs to maintain independence and neutrality to be applicable to a range of plausible decisionmaking contexts. Political buy-in is important but overreliance on specific parties can render the assessment vulnerable to change. Engaging stakeholders with different types of interest and authority, and ensuring the assessment is directed by independent groups, can allow the assessment to evolve free of political bias.

\subsection{Exchange with experts}

With increasing interest and a growing body of knowledge there is a real opportunity to take advantage of collaboration and exchange through networking and knowledge sharing. Collaborative partnerships can allow access to data, training and on the ground support. 


\subsection{Appreciate the need to understand, use and present different types of information}

Assessments are data hungry processes, and gaps will inevitably occur. Integrating information from a range of sources can circumvent some of these gaps as well as secure ownership and buy in, and contribute to a better overall understanding of the main issues. The ability to manipulate and use a range of data sources is critical to ensure gaps are handled and different data are aligned into a coherent output. Assessment teams should be prepared to engage the wider scientific community to collect data and expertise in understanding and manipulating a range of information is required. These should be key considerations when assembling a team. It will also be essential to consolidate and present information in a clear, objective, policy-relevant format. A shared analytical framework can facilitate this. Data considerations are particularly important in assessments involving indigenous groups. As well as facilitating broader participation, incorporating local/traditional knowledge can offer valuable insights that may be overseen by conventional science. In this context, there is a need to identify innovative ways to link different knowledge systems, while respecting unique cultural beliefs and settings.

\subsection{Conclusions}

Broadly speaking, almost every lesson identified relates back to buy-in, and creating an ethos of openness, communication and shared learning across diverse groups. This is not only something that needs to be sought at the beginning through 'promoting' the assessment, but opportunities arise for generating trust, ownership and mutual understanding as the process unfolds. What is more, without this buy-in, there will be little uptake of results in the communication and outreach stages. Space for learning together and learning by doing is critical for operationalisation of assessment results. This allows the development of practical implementation tools which build upon existing institutions. Assessment practitioners need to work as closely as possible with existing models, incorporating incremental change, to promote a fairer more sustainable societal system, one which works for the people, and sustains human well-being within the ecological limits of the biosphere. 


\section{REFERENCES}

Adamowicz, W., Louviere, J. \& Williams, M. (1994), Combining revealed and stated preference methods for valuing environmental amenities. Journal of Environmental Economics and Management, 26(3), 271-292.

Andrew Burger (2012), http://www.triplepundit.com/2012/11/new-teeb-business-coalition-makesbusiness-case-ecosystems-biodiversity/

Ash, N. et al. (2010), Ecosystems and Human Well-being: A Manual for Assessment Practitioners. Island Press, Washington DC

Badola, R. \& Hussain, S.A. (2005), Valuing ecosystem functions: an empirical study on the storm protection function of Bhitarkanika mangrove ecosystem India. Environmental Conservation, 32(1), 85-92.

Barbier, E.B. (2007), Valuing ecosystem services as productive inputs. Economic Policy, 22, 177-229.

Bateman, I.J., Lovett, A.A. \& Brainard, J.S. (2003), Applied Environmental Economics: a GIS approach to cost-benefit analysis. Cambridge University Press, Cambridge.

Bateman, Ian J. and Mace, Georgina M. and Fezzi, Carlo and Atkinson, Giles and Turner, Kerry (2011a), Economic analysis for ecosystem service assessments. Environmental and resource economics, 48 (2), 177-218.

Bockstael, N.E. \& McConnell, K.E. (2006), Environmental and resource valuation with revealed preferences: a theoretical guide to empirical models, the economics of non-market goods and services. Volume 7. Springer, Dordrecht.

Busch, M., La Notte, A., Laporte, V., Erhard, M. (2012), Potentials of quantitative and qualitative approaches to assessing ecosystem services. Ecological Indicators 21, 89-103.

Carson, R.C., Mitchell, R., Hanemann, W.M., Kopp, R., Presser, S. \& Ruud, P. (2003), Contingent valuation and lost passive use: damages from the Exxon Valdez oil spill. Environmental and Resource Economics, 25(3), 257-286.

Christie, M., Fazey, I., Cooper, R., Hyde, T., Kenter, J.O. (2012), An evaluation of monetary and nonmonetary techniques for assessing the importance of biodiversity and ecosystem services to people in countries with developing economies. Ecological Economics 83, 67-78.

Costanza, R., D'Arge, R., de Groot, R., Farber, S., Grasso, M., Hannon, B., Limburg, K., Naeem, S., O'Neill, R. V., Paruelo, J., Raskin, R. G., Sutton, P., and van den Belt, M. (1997), The value of the world's ecosystem services and natural capital. Nature, 387. 
Day, B.H., Bateman, I.J. \& Lake, I. (2007), Beyond implicit prices: recovering theoretically consistent and transferable values for noise avoidance from a hedonic property price model. Environmental and Resource Economics, 37(1), 211-232.

de Groot, R.S., P. Kumar, S. van der Ploeg and P. Sukhdev (2010), Estimates of monetary values of ecosystem services. In Kumar, P. (Ed.). The Economics of Ecosystems and Biodiversity: Ecological and Economic Foundations. Earthscan: London.

Duraiappah, A., K. Nakamura, K. Takeuchi, M. Watanabe and M. Nishi, eds. (2012), Satoyama-Satoumi Ecosystems and Human Well-Being: Socio-Ecological Production Landscapes of Japan. Tokyo: United Nations University Press.

EC (2012), http://www.eccb2012.org/userfiles//MAESWorkingPaper_v8_3.pdf

EC (2013), An analytical framework for ecosystem assessments under action 5 of the EU biodiversity strategy to 2020 - Discussion Paper, April 2013

EC (2014), MAES - Indicators for ecosystem assessments under Action 5 of the EU Biodiversity Strategy to 2020. Technical Report 2014-080.

Ellis, G.M. \& Fisher, A.C. (1987), Valuing the environment as input. Journal of Environmental Management, 25, 149-156.

EME (2011), Evaluación de los Ecosistemas del Milenio de España. Síntesis de resultados. Fundación Biodiversidad. Ministerio de Medio Ambiente, y Medio Rural y Marino. Madrid: Spain.

European Commission (2011), Our Life insurance, our natural capital: an EU Biodiversity to 2020 Strategy Available online: http://ec.europa.eu/environment/nature/biodiversity/comm2006/2020.htm

Farber S., Costanza R., Wilson M. (2002), Economic and ecological concepts for valuing ecosystem services. Ecological Economics 41, 375-392

Farley, J. (2012), Ecosystem services: The economics debate. Ecosystem Services 1, 40-49.

Godoy, R., Lubowski, R. \& Markandya, A. (1993), A method for the economic valuation of non-timber forest products. Economic Botany, 47, 220-233.

Haines-Young, R., Fish, R., Potschin, M., Brown, C.; Tindall, C. and S. Walmsley (2008), Scoping the potential benefits of undertaking an MA-style assessment for England. Full Technical Report to Defra (Project Code NR0118).

House of Commons Environmental Audit (2007), The UN Millennium Ecosystem Assessment. First Report of Session 2006-7; HC77, 58 pp.

ICAEW (2012), TEEB for Business Coalition prospectus. http://www.teebforbusiness.org/js/plugins/filemanager/files/TEEB-for-Business-Coalition.pdf

IPBES Catalogue of Assessments (2012a). Portugal Millennium Assessment http://ipbes.unepwcmc004.vm.brightbox.net/assessments/52 
Japan Satoyama Satoumi Assessment (2010), Satoyama-Satoumi Ecosystems and Human Well-being: Socio-ecological Production Landscapes of Japan - Summary for Decision Makers. United Nations University, Tokyo, Japan.

Kim, S, H. \& Dixon, J.A. (1986), Economic valuation of environmental quality aspects of upland agricultural projects in Korea. In J.A. Dixon \& M.M. Hufschmidt (Eds.). Economic valuation techniques for the environment: a case study workbook. Johns Hopkins Press: Baltimore.

MA (2005), Ecosystems and Human Well-being: Synthesis. Millennium Ecosystem Assessment. Island Press: Washington, D.C.

Martín-Lópeza, B., Gómez-Baggethunb, E., García-Llorentea, M., Montesa, C. (2013), Trade-offs across value-domains in ecosystem services assessment. Ecological Indicators. Online at: http://www.sciencedirect.com/science/article/pii/S1470160X1300109X

NEWP (2011), The Natural Choice: securing the value of nature http://www.officialdocuments.gov.uk/document/cm80/8082/8082.pdf

OECD (2002), Handbook of Biodiversity Valuation: A Guide for Policy Makers, OECD Publishing, Paris, http://dx.doi.org/10.1787/9789264175792-en.

OECD (2012), OECD Environmental Outlook to 2050: The Consequences of Inaction, OECD Publishing, Paris, http://dx.doi.org/ 10.1787/9789264122246-en.

Pascual, U. and R. Muradian (2010), The economics of valuing ecosystem services and biodiversity. In Kumar, P. (Ed.). The Economics of Ecosystems and Biodiversity: Ecological and Economic Foundations. Earthscan: London, UK.

Pearce, D., Atkinson, G., Mourato, S. (2006), Cost-Benefit Analysis and the Environment: Recent Developments, OECD Publishing, Paris, http://dx.doi.org/10.1787/9789264010055-en.

Sub-Global Assessment Network (2012a), Undertaking Ecosystem Assessments in the Country of Panlusia. Workbook 1: The Exploratory Stage. UNEP-WCMC.

Sub-Global Assessment Network (2012b), Lesson learned from carrying out ecosystem assessments: Experiences from members of the Sub-Global Assessment Network. UNEP-WCMC and The Cropper Foundation.

TEEB (2010), The Economics of Ecosystems and Biodiversity: Mainstreaming the Economics of Nature: A synthesis of the approach, conclusions and recommendations of TEEB. UNEP, 2-39.

TEEB (2011), TEEB Processes in European Countries. International Academy for Nature Conservation, Isle of Vilm, Germany

TEEB (2012), Natural Capital at risk: a study of the top 100 business impacts.

TEEB (2013),TEEB for Business Coalition. http://teebforbusiness.org/activities/

Turner, R.K., Morse-Jones, S., Fisher, B., (2010), Ecosystem valuation. Annals of the New York Academy of Sciences. 1185, 79-101. 
UK NEA (2011), The UK National Ecosystem Assessment: Synthesis of the Key Findings. UNEP-WCMC, Cambridge.

UNEP/GC.25/INF/12 Overview of the environmental assessment landscape at the global and regional levels

$\mathrm{UNEP/IPBES/3/INF/1} \mathrm{Analysis} \mathrm{of} \mathrm{the} \mathrm{assessment} \mathrm{landscape} \mathrm{for} \mathrm{biodiversity} \mathrm{and} \mathrm{ecosystem} \mathrm{services}$

UNEP/1/INF/8 Critical review of the assessment landscape for biodiversity and ecosystem services

UNEP and IOC-UNESCO (2009), An Assessment of Assessments, Findings of the Group of Experts.

Start-up Phase of a Regular Process for Global Reporting and Assessment of the State of the Marine Environment including Socio-economic Aspects. ISBN 978-92-807-2976-4

U.S. Environmental Protection Agency (EPA). (2008), EPA's 2008 Report on the Environment. National Center for Environmental Assessment, Washington, DC; EPA/600/R-07/045F. Available from the National Technical Information Service, Springfield, VA, and online at http://www.epa.gov/roe.

Wegner, G., Pascual, U. (2011), Cost-benefit analysis in the context of ecosystem services for human well-being: A multidisciplinary critique. Global Environmental Change 21, 492-504.

Wilson, M., Howarth, R.B. (2002), Discourse-based valuation of ecosystem services: establishing fair outcomes through group deliberation. Ecological Economics 41, 431-443. 


\section{ANNEX 1. SUMMARY OF VALUATION METHODS}

\section{Direct market valuation}

These approaches seek to calculate values from observed market data by linking them directly to market prices, productivity or production costs.

1. Market price methods calculate values for products sold and brought at commercial markets based on market price data. These methods, thus, most often can only estimate the direct use value of ecosystem services (crops, fibre, water, etc.). See Godoy et al. (1993) and Bateman et al. (2003) as examples.

2. Cost-based methods estimate direct and indirect use values of ecosystem services from i) the damage costs of losing these ecosystem services (e.g. health costs from heat waves, reconstruction after natural disasters), b) the cost of replacing these ecosystem services (e.g. buying forest products at the market instead of collecting them from a nearby forest, installing air conditioning, building dams) or c) the costs of mitigating the effects of losing these services and of restoring lost services (e.g. reforestation, rehabilitation of natural habitat). See Kim \& Dixon (1986), and Badola \& Hussain (2005) as examples.

3. Production-based methods estimate the value of ecosystem services that serve as an input in the production of a marketed good modelling a) production functions or b) factor income equations (e.g. linking pollination to agricultural production or genetic diversity to the development of new pharmaceutical products.). See Ellis \& Fisher (1987) and Barbier (2007) as examples.

\section{Revealed preference methods}

These methods seek to reveal people's willingness-to-pay (WTP) for ecosystem services from choices made in real markets context. The difference to direct market valuation is that observed behaviour is not directly related to the economic benefits from ecosystem services.

1. Travel costs method calculate time and travel costs people incur to visit an area that provides unique ecosystem services (a natural park with high biodiversity, visiting a rainforest resort with a unique animal species, a beach with intact mangroves). See Bockstael and McConnell (2006) as an example.

2. Hedonic pricing method attempt to derive the implicit price for a ecosystem services by modeling observable prices for a product on a set of explaining variables including proxies for ecosystem services (e.g. calculate the price premium people are willing to pay for high water quality or for staying in an ecotourism resort with high biodiversity). See Day et al. (2007) as an example. 


\section{Stated preference methods}

These approaches seek to derive values for ecosystem services by identifying people's preferences in hypothetical market contexts. Their main strength as opposed to the other approaches is that they can be designed for any ecosystem services context. Compared to the market-based valuation and revealed preference methods, they can also capture non-use values.

1. Contingent valuation is based on surveys asking people if they are they are willing to pay a certain hypothetical price for a change in an ecosystem and related ecosystem services or if they would be willing to accept a certain hypothetical compensation for ecosystem degradation or loss of ecosystem services. See Carson et al. (2003) as an example.

2. Choice experiments model decision-making processes from data related to people ranking/choosing of a limited number of hypothetical options. Each of these options is related to a number of choice attributes with attribute levels varying between choice options. If one of these attributes is closely linked to an ecosystem services (e.g. maintaining drinking water quality at a high, medium low levels), monetary values for this ecosystem services can be estimated. See Adamowicz et al. (1994) as an example.

3. Group valuation exercises are deliberative and participatory methods whereby a wider group of people discusses how their well-being would be affected by a change in an ecosystem. Values are not necessarily expressed in monetary terms and the focus is on group processes and collective values and not on individual preferences (Wilson and Howarth, 2002). As such these methods can be used to account for values form social benefits.

\section{Benefit transfer methods}

Given time and budget constraints the above outlined methods often cannot be undertaken to establish ecosystem services values at national scale. Yet there are a growing number of studies applying benefit transfer methods, whereby benefit values for a study are transferred from an existing core of original studies undertaken in similar contexts using various adjustment techniques.

1. Unit benefit transfer is based on the average ecosystem services value from another site (expressed in per person or per land unit terms) and calculates the total ecosystem services value in the study site by multiplication with population size or land area.

2. Adjusted unit transfer is based on the same average value but makes adjustments for the study site population (e.g. living standards) or ecosystem characteristics (e.g. tree coverage).

3. Value/demand function transfer methods use parameters estimated from a regression model determining a value/demand function in another site (e.g. importance of slope and rainfall intensity in explaining soil sedimentation control values). These parameters are then combined with data from the study site on the variables relevant for the ecosystem services value/demand function.

4. Meta-analytic function transfer methods use information from a number of valuation studies from other sites. These are combined in a meta-regression so as to estimate parameters for the aggregated ecosystem services value or demand function. Then these aggregated parameters are applied to the study site characteristics as above. Compared to a value/demand function transfer a meta-analytic function allows for greater flexibility covering a range of studies undertaken in different contexts. 
ENV/WKP(2014)9 